\title{
The potential use of crushed waste glass as a sustainable alternative to natural and manufactured sand in geotechnical applications
}

\author{
Danish Kazmi ${ }^{\text {a; }}$ Mehdi Serati a, David J. Williams ${ }^{\text {a }}$; Sadaf Qasim ${ }^{\text {b; }}$ Yi Pik Cheng ${ }^{\text {c }}$ \\ a Geotechnical Engineering Centre, School of Civil Engineering, The University of Queensland, Brisbane, QLD, \\ 4072, Australia \\ ${ }^{\mathrm{b}}$ Department of Civil Engineering, NED University of Engineering and Technology, Karachi, 75270, Pakistan \\ ${ }^{\mathrm{C}}$ Department of Civil, Environmental and Geomatic Engineering, University College London, London, \\ WC1E 6BT, United Kingdom
}

\begin{abstract}
The increasing price and diminishing reserves of construction sand encourage a need to develop its sustainable and cost-effective replacement, helping the transition towards a circular economy. Waste glass is a derivative of natural sand and could potentially show similar geotechnical behaviour. Using crushed waste glass $(\mathrm{CWG})$ as an alternative to traditional sand would potentially offer a double-duty benefit by helping to address the geo-environmental challenges of natural sand depletion and disposal of ever-increasing waste glass, together. This study investigated the geotechnical, mineralogical and morphological behaviour of CWG and compared it with that of natural sand (NS) and manufactured sand (MS). The geotechnical characterisation results showed that the behaviour of CWG is similar to the other two sands studied, with CWG showing the highest permeability and abrasion resistance. Surprisingly, the shear strength testing showed that the friction angle of CWG was higher under saturated conditions than under dry conditions, indicating the stability of CWG under saturated conditions. The mineralogical analysis was conducted using x-ray fluorescence (XRF) spectroscopy and revealed that silica is the dominant mineral in all three materials, indicating a similarity in their chemical composition. The morphological analysis was performed to quantify the particle shape of each material in terms of roundness index using digital images obtained through an optical microscope. The results demonstrated that MS showed the highest particle angularity, followed by CWG and NS. Overall, it was concluded that CWG could potentially act as a next-generation alternative and smart geomaterial, replacing traditional sands in several geotechnical applications.
\end{abstract}

\section{Keywords}

Construction sand; circular economy; crushed waste glass; $x$-ray fluorescence (XRF)

spectroscopy; optical microscope; smart geomaterial

\section{List of abbreviations}

$\begin{array}{ll}\text { NS } & \text { Natural sand } \\ \text { MS } & \text { Manufactured sand } \\ \text { CWG } & \text { Crushed waste glass } \\ \text { XRF spectroscopy } & \text { X-ray fluorescence spectroscopy } \\ \text { LVDT } & \text { Linear variable differential transformer } \\ \text { OM } & \text { Optical microscopy } \\ \text { CLT } & \text { Central limit theorem } \\ \text { NSE } & \text { Nash-Sutcliffe model efficiency coefficient } \\ \text { SF } & \text { Normalised shape factor }\end{array}$




\section{Introduction}

Natural aggregates are widely used in a range of applications. Presently, the construction industry is the biggest consumer of natural resources in the world (Bogas et al., 2015). It is a common practice to crush and screen the rock formations to different specifications, producing aggregates suitable for different construction applications (Xu et al., 2018a). The global consumption of aggregates is expected to increase at a rate of 5\% per annum (Dhir et al., 2019). Major sources of natural construction aggregates include crushed stone, gravel, and sand (Kelly, 1998). In Australia alone, nearly 130 million tonnes of aggregates are extracted each year, which is expected to further increase in the coming years (Cement Concrete and Aggregates Australia, 2011). A key concern for sustainable infrastructure construction is the continuous diminution of readily-available construction aggregates (Holmstrom \& Swan, 1999). Environmentally, the extraction and logistics of aggregates release carbon footprint, which is harmful to the ecosystem (Bravo et al., 2015). Consequently, nowadays, construction materials are increasingly being evaluated by their ecological footprint (Hebhoub et al., 2011).

Natural sand is a widely used raw material and has become the second-most widely consumed natural resource on planet Earth, after freshwater (WACA, 2018). It is estimated that between 32 and 50 billion tonnes of sand and gravel are extracted globally each year, which is largely used in construction (Koehnken \& Rintoul, 2018). As an example, the construction of a medium-sized house requires 200 tonnes of sand; a hospital needs 3000 tonnes of sand, and each kilometre of highway construction needs 30,000 tonnes of sand (WACA, 2018). Studies show that sand is currently being extracted at a rate far greater than its renewal (Peduzzi, 2014). Indiscriminate mining of sand could endanger animal species and habitats, harm aquatic life and cause biodiversity loss (Koehnken et al., 2020). It could also cause beach erosion, making coastal communities vulnerable to floods and causing loss to the eco-tourism industry (Jonah et al., 2015). It is, therefore, necessary to find ways to reduce the demand for natural sand and to look for sustainable and low-carbon alternatives.

One of the ways of reducing the consumption of natural sand is to utilise wastes as an alternative material (Emery, 1974). Recycling of wastes could reduce the demand for virgin natural resources and help to dispose of them effectively (Kazmi et al., 2019b). The volumes of wastes generated each year are alarmingly increasing due to a rise in the global population. The world produces nearly 2.0 billion tonnes of municipal solid waste every year, which is expected to grow to 3.4 billion tonnes by 2050 (Kaza et al. 2018). In Australia, nearly 67 million tonnes of waste was produced in 2016-17, equivalent to 2.7 tonnes per capita per year (Pickin et al., 2018). Statistics show that around $40 \%$ of waste is landfilled each year in Australia (Department of the Environment and Energy, 2013). It is imperative to minimise the amount of solid waste landfilled every year to promote environmental sustainability, waste valorisation and to minimise resource consumption (Vining et al., 1992). Typically, recycling is regarded as an eco-friendly strategy for solid waste management that is superior to landfilling or incineration (Peng et al., 1997). Besides the conservation of energy and materials, recycling typically decreases the need for landfilling and incineration, reduces pollution, and contributes positively to the environment (Woodford, 2019).

Waste glass, sometimes also called cullet, is commonly found in mixed waste. Statistics show that volumes of waste glass generated every year are constantly increasing. In 2016, the waste glass accounted for $5 \%$ of the total waste generated globally (Kaza et al. 2018). In Australia alone, nearly 1.1 million tonnes of waste glass was produced in 2016-17, with $43 \%$ remaining unrecycled. The stockpiles of waste glass are continuously increasing, creating a disposal challenge (Arulrajah et al., 2012b). According to the European Union (EU) statistical data, glass is the third most common packing material. In 2017, the EU generated nearly $173.8 \mathrm{~kg}$ 
of packaging waste per capita, comprising a huge 18\% glass (Eurostat, 2020). Although colourless glass could be used for glass re-manufacturing, the multi-coloured waste glass is often sent for landfilling (Park \& Lee, 2004). A key reason limiting the use of waste glass for glass-remanufacturing is the expensive colour sorting of waste glass fragments necessary to avoid colour contamination, making its use often uneconomical in glass re-manufacturing due to a substantial increase in the cost of furnace-ready cullet (Amiri et al., 2018). Moreover, the colour sorting of waste glass is sometimes impractical, because a large volume of waste glass supplied to the recycling industry is broken into smaller fragments during the logistics, making it difficult to colour sort waste glass due to its smaller particle size (Arulrajah et al., 2015).

Glass is relatively inert and could take several hundred years to biodegrade (Salamatpoor \& Salamatpoor, 2017). Waste glass not only consumes precious landfill space, but it also causes environmental pollution Jani \& Hogland (2014); making landfilling of waste glass an environmentally unsustainable solution (Rashad, 2014). The increasing scarcity of landfill spaces necessitates the development of new and self-sustaining applications of waste glass, together with finding ways to promote its recycling. Greater recycling of waste glass would reduce pressure on landfills and promote the circular economy, an economic model wherein planning, resourcing, procurement, production and reprocessing are designed and managed to maximise human well-being and ecosystem functioning (Murray et al., 2017). This model has been proposed as an alternative to the traditional linear-extract-produce-use-dump material and energy flow model, which is increasingly unsustainable (Frosch \& Gallopoulos, 1989). The circular economy model promotes minimising wastes by utilising them as an input for other applications, thereby promoting recycling (Stahel, 2016).

Crushed waste glass (CWG) has been studied for use in various secondary applications. For example, CWG has been studied as a fluxing agent for decreasing the firing temperature required in ceramic production (Shishkin et al., 2020). Similarly, Shishkin et al. (2019) investigated CWG as an additive for the production of clay-glass aggregate for building construction. Marangoni et al. (2014) analysed the use of CWG for the production of glassceramic foams. Chen et al. (2020) explored the fire resistance performance of cementitious composites containing CWG. Several studies have shown that CWG may be partially used as supplementary cementitious material and alternative to fine-grained aggregates in concrete production (Kazmi et al., 2019b). These applications, among others, typically utilise only some of the CWG produced (generally less than $40 \%$ ). Limited geotechnical engineering studies have shown that CWG could potentially be used as a backfilling material in embankments, drainage blankets and road pavements. However, the use of CWG could be extended to other geotechnical applications, such as granular piles, which could potentially consume a much greater amount of CWG, possibly fully replacing traditional sand with CWG. Moreover, due to the absence of cementitious material containing alkali, several geotechnical applications, such as granular piles, could potentially utilise multi-coloured glass as an alternative to traditional aggregates, which could help divert waste glass from landfills.

One of the ways to recycling waste glass is to use it as a sustainable alternative to diminishing and increasingly expensive natural sand. Both sand and waste glass have a similar chemical composition and contain silica as a primary mineral. Typically, waste glass has angular particles and exhibits geotechnical parameters similar to natural aggregates (Arulrajah et al., 2012a). Using CWG as a replacement for natural sand could potentially offer two-pronged environmental and economic benefits, including a decrease in greenhouse gas emissions due to quarrying activities, reduction in an ever-increasing demand for natural sand, conservation of virgin sand reserves, reduced travelling time and distance of sand, and greater cost- 
effectiveness (Kazmi et al., 2019a). Simultaneously, it would potentially have a knock-on effect of providing socio-economic benefits, promoting sustainable resource recovery, reducing landfill burden and developing a sustainable supply chain of waste glass. Presently, a lack of knowledge on the geotechnical behaviour of CWG is the biggest barrier in its use in geotechnical projects (Disfani et al., 2011b). In civil engineering, previous literature shows that the use of CWG has been mostly studied in concrete as an alternative to fine-aggregates and as supplementary cementitious material (Jani \& Hogland, 2014). However, the studies exploring the geotechnical potential of CWG are relatively limited, mainly involving its use in road pavements and as soil additive; potentially due to a knowledge gap on the geo-environmental behaviour of CWG (Disfani et al., 2011a). This research aims to develop new geotechnical applications of CWG as an alternative geomaterial by comparing its behaviour with traditional sands.

\section{Materials and Methodology}

Motivated by the above observations, this study compared the geotechnical potential of CWG with that of traditionally-used natural sand (NS) and manufactured sand (MS), which comes from two major sources of construction sand, i.e. beach and quarry. NS and MS were obtained from the beach of Pine River and from Mount Coot-tha quarry respectively in Queensland, Australia. CWG was obtained from a commercial supplier, Enviro sand, in Brisbane, utilising $100 \%$ recycled glass, and milling it using a mining crusher under near-dry conditions (less than $2 \%$ moisture content).

The experimental program involves performing three different analyses, including geotechnical, mineralogical and morphological, on the three materials. A key motivation to conduct the mineralogical analysis was to determine the silica content, which is typically a primary mineral in both sand and glass. X-ray fluorescence (XRF) spectroscopy was used to perform the mineralogical analysis on the three samples, using a fused bead Li-borate technique with an energy-dispersive X-ray fluorescence spectrometer (ED-XRF), XEPOS HE, (Spectro, Germany). The Spectro XEPOS HE is a dual anode system with palladium (Pd) for high energy excitation and cobalt $(\mathrm{Co})$ for low energy excitation. The accelerating voltage is increased over the range 6 to $19 \mathrm{keV}$ (elements Co to U), but the elements with X-ray lines lower than $6 \mathrm{keV}$ (lighter than $\mathrm{Co}$ ) are less excited. The range between $3 \mathrm{keV}$ and $6 \mathrm{keV}$ (elements $\mathrm{K}$ to $\mathrm{Fe}$ ) incorporates bandpass and polarising filters using the Co target. The region below $3 \mathrm{keV}$ uses the L-spectral lines of the Pd target and a polarising target for increased sensitivity. The Spectro $E D-X R F$ measures three energy ranges, which were optimised for the ranges of interest (i.e. $<3 \mathrm{keV}, 3$ to $6 \mathrm{keV}$ and 6 to $19 \mathrm{keV}$ ).

The geotechnical analysis initially involved characterisation testing, including the sieve analysis, hydraulic conductivity, specific gravity, densities, and abrasion loss. The specific gravity and hydraulic conductivity of the materials were determined using the Helium gas pycnometer and constant head permeability test, respectively.

Afterwards, shear strength testing was performed using a direct shear apparatus. According to Das (2009), the direct shear apparatus comprises a split metal box in which the sample is placed. Figure 1 shows the arrangement of the direct shear test. The normal force on the sample is applied vertically using dead weights. The shear force is applied by moving the top half of the shear box relative to the fixed bottom half, causing shearing of the sample at the interface between the two halves of the shear box. During the experiment, the change in sample thickness and shear displacement of the top half are recorded using dial gauges or linear variable differential transformers (LVDTs). The shear strength parameters of the sample are then interpreted from the test results (Xu et al., 2018). 


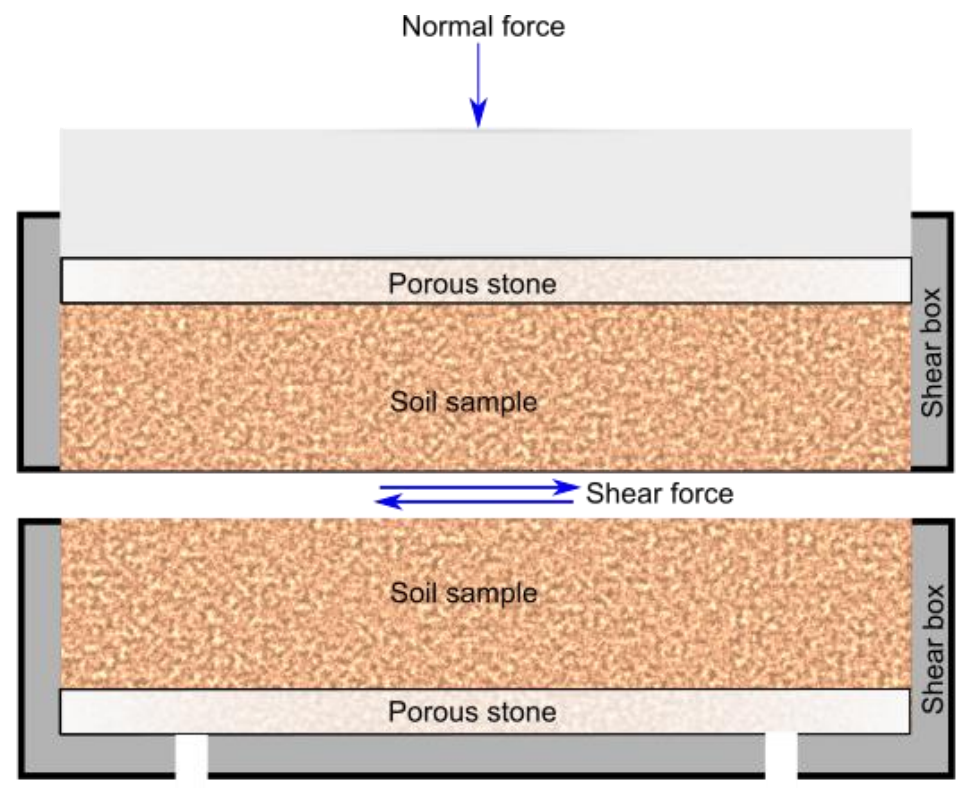

Fig.1. Direct shear test arrangements (Adapted from Das (2009))

The direct shear testing involved preparing the oven-dried samples in a loose-dry condition with dimensions $60 \times 60 \times 32 \mathrm{~mm}$. Seven normal stresses, 6.8, 13.6, 27.2, 54.5, 109.0, 218.0 and $436.0 \mathrm{kPa}$, were applied under dry and saturated conditions. The saturated condition refers to testing in a bath, which for a sandy material would achieve full saturation.

An important parameter used to evaluate the suitability of material in construction applications is abrasion resistance, which is the ability of a surface to withstand degradation due to friction or rubbing (Safiuddin \& Scott, 2015). Technically, the resistance of aggregates to degradation is typically a combination of two phenomenons, including abrasion, denoting loss in the surface angularity of aggregate, and breakage, which refers to the fracturing of particles (Mahmoud, 2007). In construction, the aggregates are typically required to be tough and abrasion-resistant to withstand degradation, crushing and disintegration during various activities ( $\mathrm{Wu}$ et al., 1998). It is, therefore, essential to evaluate the resistance to degradation of any alternative geomaterial before considering its use in construction. The abrasion loss in CWG was compared to that of NS and MS. Micro-Deval apparatus was used to perform the abrasion testing.

Moreover, the morphological analysis was conducted using a digital imaging technique to determine the particle shape (angularity) of the three materials. An optical microscope, containing a digital colour camera Leica DFC295 with a pixel depth of $3.2 \mu \mathrm{m} \times 3.2 \mu \mathrm{m}$, was used to image the sample particles followed by the analysis of microscopic images using an image processing software ImageJ. The shape of sample particles was calculated in terms of roundness index $\left(R_{i}\right)$ using the following equation as proposed by Wadell (1932).

$$
R_{i}=\frac{\sum_{\mathrm{i}=1}^{\mathrm{N}} \mathrm{r}_{\mathrm{i}} / \mathrm{N}}{\mathrm{R}}
$$

Where, $\mathrm{r}_{\mathrm{i}}$ is the radius of corners of the particle, $\mathrm{N}$ is the number of corners, and $\mathrm{R}$ is the radius of the largest inscribed circle. Figure 2 shows the graphical illustration to calculate the radii of the particle. 


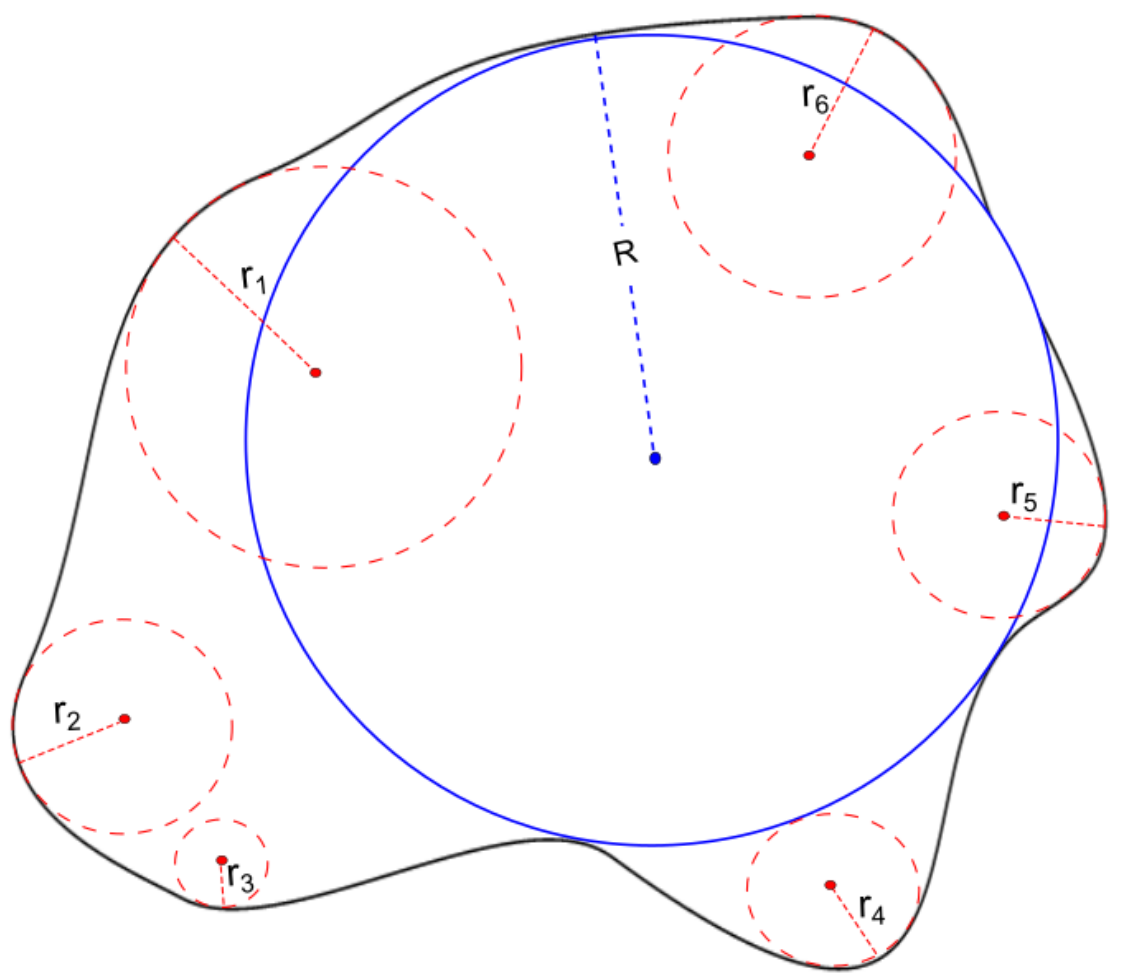

Fig.2. Graphical illustration for calculating the radii of a particle

The optical microscopy $(\mathrm{OM})$ images were input into ImageJ software to calculate particle's roundness index, which is the ratio of the mean radius of curvature of the corners of the particle's silhouette to the radius of the largest inscribed circle. The particle roundness index was determined using the method proposed by Wadell (1932). A roundness index value of 1 represents a perfectly round particle, whereas 0 represents an angular one. Overall, a total of 390 particles (i.e. grains) of each material were analysed for particle shape calculations. Afterwards, the central limit theorem (CLT) was applied to estimate the mean roundness index and to assess whether the particle roundness in each material has a normal distribution. The results from the CLT can also be used to get an idea of the minimum number of particles (grains) required to collect from each material for statistical analysis. According to CLT, given a sufficiently large sample size (usually $\mathrm{N}>30$ ) selected from a population with a finite variance level, the mean of all sample sets drawn randomly from the population (with replacement) will be equal to the population mean (i.e. $\mu$ ), regardless of the population shape and distribution (Ganti, 2019). That is, the sampling distribution of the sample means drawn from a population with any distribution is approximately normally distributed with a mean $\left(\mu_{\bar{X}}\right)$ equals to the population mean (i.e. $\mu=\mu_{\bar{X}}$ ). It should be noted that if the original population (from which the data is drawn) is normal itself, the sampling distribution of the sample means becomes normally distributed even for small sample sizes (e.g. $\mathrm{N}>5$ ). The standard deviation of the sampling distribution of sample means $\left(\sigma_{\bar{X}}\right)$ is also related to the population's standard deviation according to:

$$
\sigma_{\bar{X}}=\frac{\sigma}{\sqrt{N}}
$$

Where $\sigma_{\bar{X}}$ and $\sigma$ represents the standard deviation of the sampling distribution of sample means and the population, respectively, with $\mathrm{N}$ representing the sample size. Different samples with a size of 5, 10, 15, 20 and 25 particles were randomly selected from each material, and their frequency distribution was plotted. Some manual adjustments were performed to ensure the grains were clearly defined and did not overlap during imaging. 


\section{Geotechnical characterisation of materials}

242 Figure 3 illustrates the gradation curves of the materials, while the gradation parameters are shown in Table 1. The results of sieve analysis showed that NS and CWG are uniformly graded materials, with a median grain diameter of $0.29 \mathrm{~mm}$ and $1.42 \mathrm{~mm}$, respectively. The coefficient of uniformity $\left(\mathrm{C}_{\mathrm{u}}=\mathrm{D}_{60} / \mathrm{D}_{10}\right)$ and the coefficient of curvature $\left(\mathrm{C}_{\mathrm{c}}=\mathrm{D}_{30} /\left(\mathrm{D}_{60} \times \mathrm{D}_{10}\right)\right)$ for NS was found to be 1.43 and 0.94 , respectively. Similarly, the coefficient of uniformity and curvature for CWG were found to be 2.21 and 0.96, respectively. Nevertheless, MS showed a well-graded gradation with a median grain diameter, coefficient of uniformity and coefficient of curvature of $1.55 \mathrm{~mm}, 13.37$ and 1.51, respectively. The potential reason for a uniform gradation and smaller grain size of NS could be its process of deposition, governed primarily by wave action and ebb and flow of tides. For MS and CWG, the grain size and gradation are a function of several factors, such as the degree of crushing, sorting and sieving. Table 2 shows the geotechnical parameters of the materials. The specific gravity of all three materials was comparable to each other and ranging 2.50-2.74, with MS and CWG having the maximum and minimum specific gravity, respectively. The potential reason for similar specific gravity of NS, MS and CWG could be the presence of silica as a primary mineral, considering that glass is essentially a derivative of sand. Previous literature shows that the permeability of CWG could be particularly sensitive to the presence of contaminants, such as organic content and debris (Dhir et al., 2018). The results of permeability tests demonstrated that CWG had the highest hydraulic conductivity, followed by NS and MS. The higher permeability of CWG could potentially be attributed to its uniform gradation and larger effective diameter $\left(\mathrm{D}_{10}\right)$, causing a relatively higher maximum void ratio; noting that permeability of sands is directly proportional to their effective diameter (Hazen, 1892). CWG typically offers superior permeability characteristics, indicating its potential to act as a drainage media in various geotechnical applications (Disfani et al., 2011b).

The results of abrasion testing showed that CWG, surprisingly, outperformed NS and MS. It was observed that abrasion loss in CWG was nearly two and four times less than that of NS and MS, respectively (see Table 2); favouring the prospects of using CWG as an alternative geomaterial in traditional geotechnical applications. 


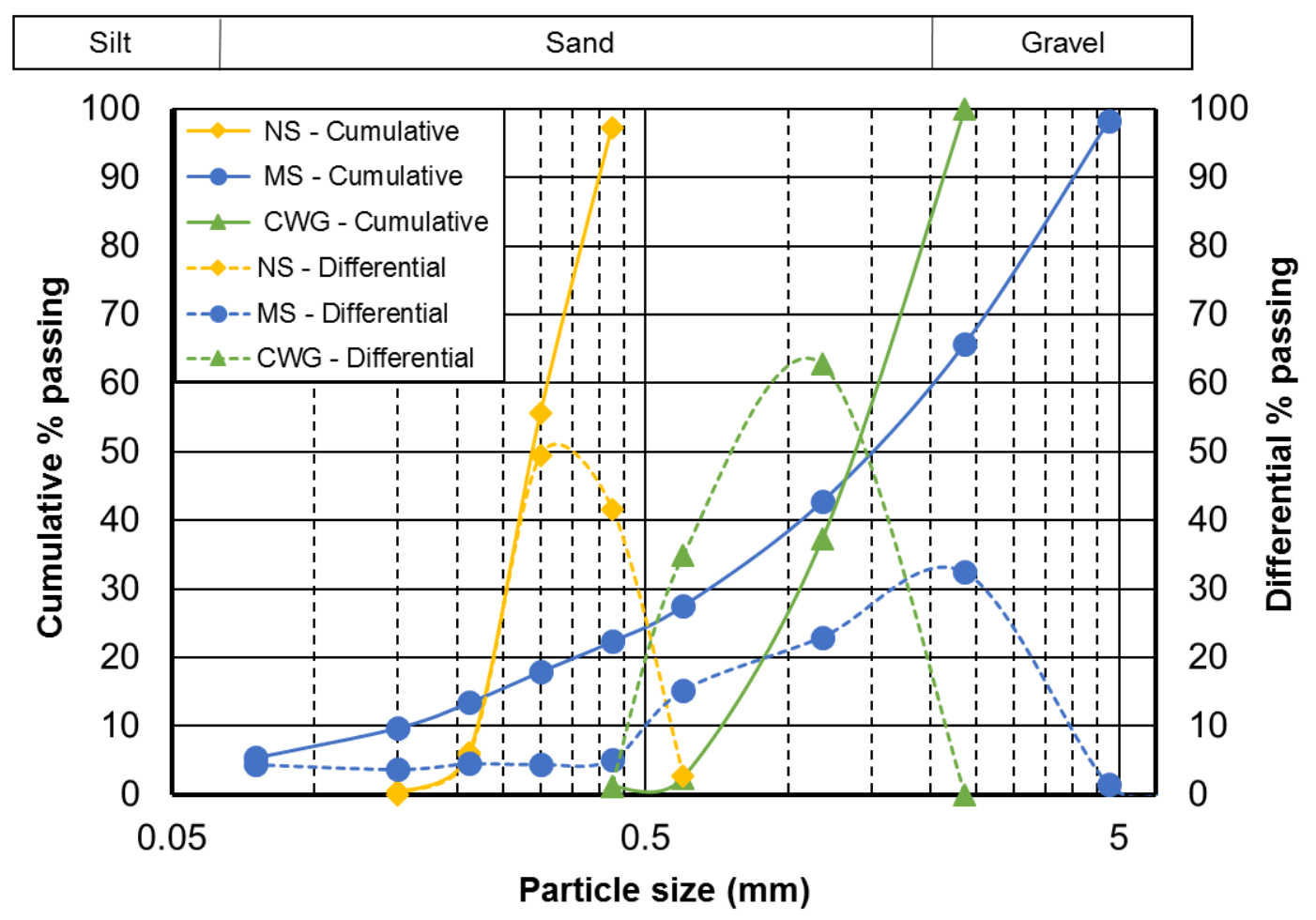

Fig.3. Gradation curves of the materials

271 Table 1. Gradation parameters of the materials

\begin{tabular}{|c|c|c|c|}
\hline & NS & MS & CWG \\
\hline $\mathrm{C}_{\mathrm{u}}$ & 1.43 & 13.37 & 2.21 \\
\hline $\mathrm{C}_{\mathrm{c}}$ & 0.94 & 1.51 & 0.96 \\
\hline $\mathrm{D}_{60}(\mathrm{~mm})$ & 0.31 & 2.07 & 1.61 \\
\hline $\mathrm{D}_{50}(\mathrm{~mm})$ & 0.29 & 1.55 & 1.42 \\
\hline $\mathrm{D}_{30}(\mathrm{~mm})$ & 0.25 & 0.69 & 1.06 \\
\hline $\mathrm{D}_{10}(\mathrm{~mm})$ & 0.22 & 0.15 & 0.73 \\
\hline
\end{tabular}

272 Table 2. Geotechnical parameters of the materials

\begin{tabular}{|c|c|c|c|c|}
\hline & NS & MS & CWG & Standard \\
\hline Minimum void ratio & 0.59 & 0.39 & 0.37 & - \\
\hline Maximum void ratio & 0.70 & 0.62 & 0.79 & - \\
\hline $\begin{array}{c}\text { Gravimetric moisture } \\
\text { content (\%) }\end{array}$ & 3.08 & 0.33 & 0.00 & AS 1289.2.1.1-2005 \\
\hline Specific gravity & 2.63 & 2.74 & 2.50 & ASTM D5550 -14 \\
\hline Liquid limit (\%) & 22.72 & 19.33 & - & AS 1289.3.9.1:2015 \\
\hline $\begin{array}{c}\text { Minimum dry density } \\
\left(\mathrm{g} / \mathrm{cm}^{3}\right)\end{array}$ & 1.54 & 1.69 & 1.39 & AS 1289.5.5.1-1998 \\
\hline $\begin{array}{c}\text { Maximum dry density } \\
\left(\mathrm{g} / \mathrm{cm}^{3}\right)\end{array}$ & 1.65 & 1.96 & 1.82 & AS 1289.5.5.1-1998 \\
\hline $\begin{array}{c}\text { Hydraulic } \\
\text { conductivity (m/s) }\end{array}$ & $3.81 \times 10^{-4}$ & $3.59 \times 10^{-4}$ & $4.01 \times 10^{-4}$ & ASTM D2434-68 \\
\hline Abrasion loss (\%) & 6.00 & 9.60 & 2.40 & ASTM D7428 \\
\hline
\end{tabular}




\section{Experimental Results}

\subsection{Direct shear tests to determine the friction angles}

Oven-dried materials were used to prepare the direct shear samples in loose conditions. These samples were subjected to direct shear testing at a shearing rate of $1.0 \mathrm{~mm} / \mathrm{min}$. The measured shear stresses and applied normal stresses were corrected for reductions in the shear area during the shearing process (Xu et al., 2018b). The shear strength envelopes were best-fitted by applying the Mohr-Coulomb failure criterion. The value of cohesion (c) was set to zero as uncemented sand does not typically exhibit cohesion. The fitting parameters are shown for each of the envelopes in terms of the coefficient of determination $\left(\mathrm{R}^{2}\right)$ and the Nash-Sutcliffe model efficiency coefficient (NSE). The NSE was proposed by Nash and Sutcliffe (1970) to provide a goodness-of-fit-index relatively superior to the correlation coefficient. One advantage of the NSE is that it can be applied to a range of model types (McCuen et al., 2006). Several researchers have previously applied the NSE in geotechnical engineering research, showing that the NSE provides a more reliable statistical estimate of the goodness-of-fit (Mishra et al., 2017; Mishra et al., 2018). An NSE value of 1 represents an ideal agreement between the model and observed values (Criss \& Winston, 2008). Based on the NSE criteria proposed by Chiew and McMahon (1993), the goodness-of-fit of all shear strength envelopes presented in this study can be classified as "perfect" (NSE $\geq 0.93$ ).

Table 3 compares the peak and final friction angles of materials under dry and saturated conditions. Figure 4 and 5 show the peak shear strength envelopes of materials under dry and saturated conditions, respectively. Figure 6 and 7 shows the final shear strength envelopes of materials under dry and saturated conditions, respectively. The results indicated that the peak friction angle of MS under dry conditions was found to be the highest, $44.9^{\circ}$, followed by that of NS $\left(36.9^{\circ}\right)$ and CWG $\left(35.5^{\circ}\right)$. Potential reasons for a relatively higher friction angle of MS include relatively well-graded gradation and larger particle size, contributing to a lower void ratio and higher inter-particle contact points. The highest angularity (i.e. lowest roundness index, as shown in Table 6) of the MS could be a reason. Previous studies have also endorsed that sands exhibiting a relatively higher friction angle typically have coarser-grained particles, well-graded gradation and angular shape (Bareither et al., 2008).

Table 3. Comparison of peak and final friction angles of the materials under dry and saturated conditions

\begin{tabular}{|c|c|c|c|c|c|c|}
\hline \multirow{4}{*}{} & \multicolumn{2}{|c|}{ NS } & \multicolumn{2}{c|}{ MS } & \multicolumn{2}{c|}{ CWG } \\
\cline { 2 - 8 } & \multicolumn{7}{|c|}{\begin{tabular}{c}
\multicolumn{2}{c|}{ Peak } \\
\cline { 2 - 8 } $\begin{array}{c}\text { Angle of } \\
\text { internal friction } \\
\left({ }^{\circ}\right)\end{array}$
\end{tabular}} & Dry & Saturated & Dry & Saturated & Dry & Saturated \\
\cline { 2 - 8 } & 36.9 & 34.4 & 44.9 & 43.0 & 35.5 & 39.0 \\
\cline { 2 - 8 } & 31.1 & 30.7 & 44.1 & 41.3 & 29.1 & 32.4 \\
\hline
\end{tabular}




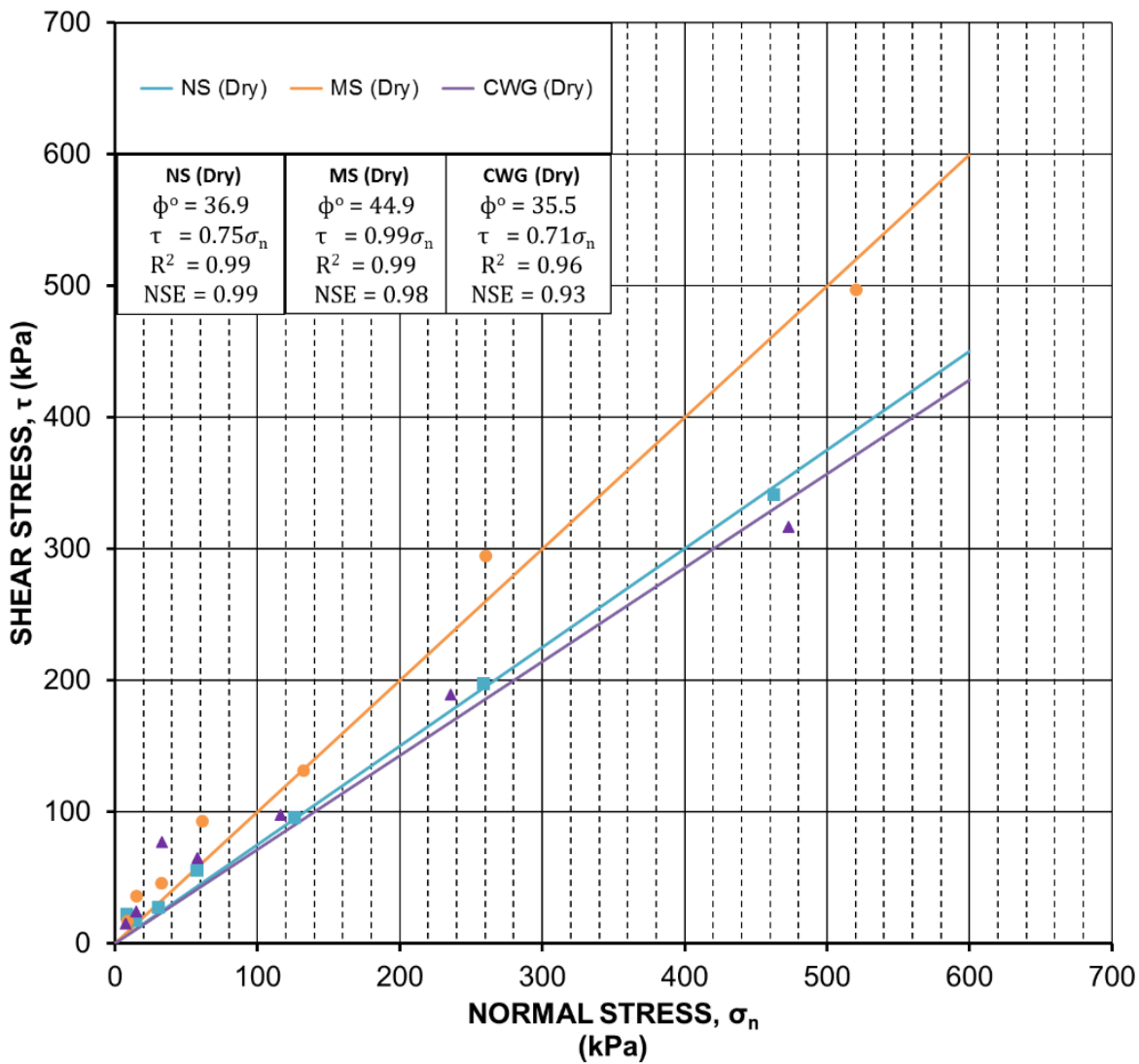

Fig.4. Peak shear strength envelopes of the materials under dry conditions

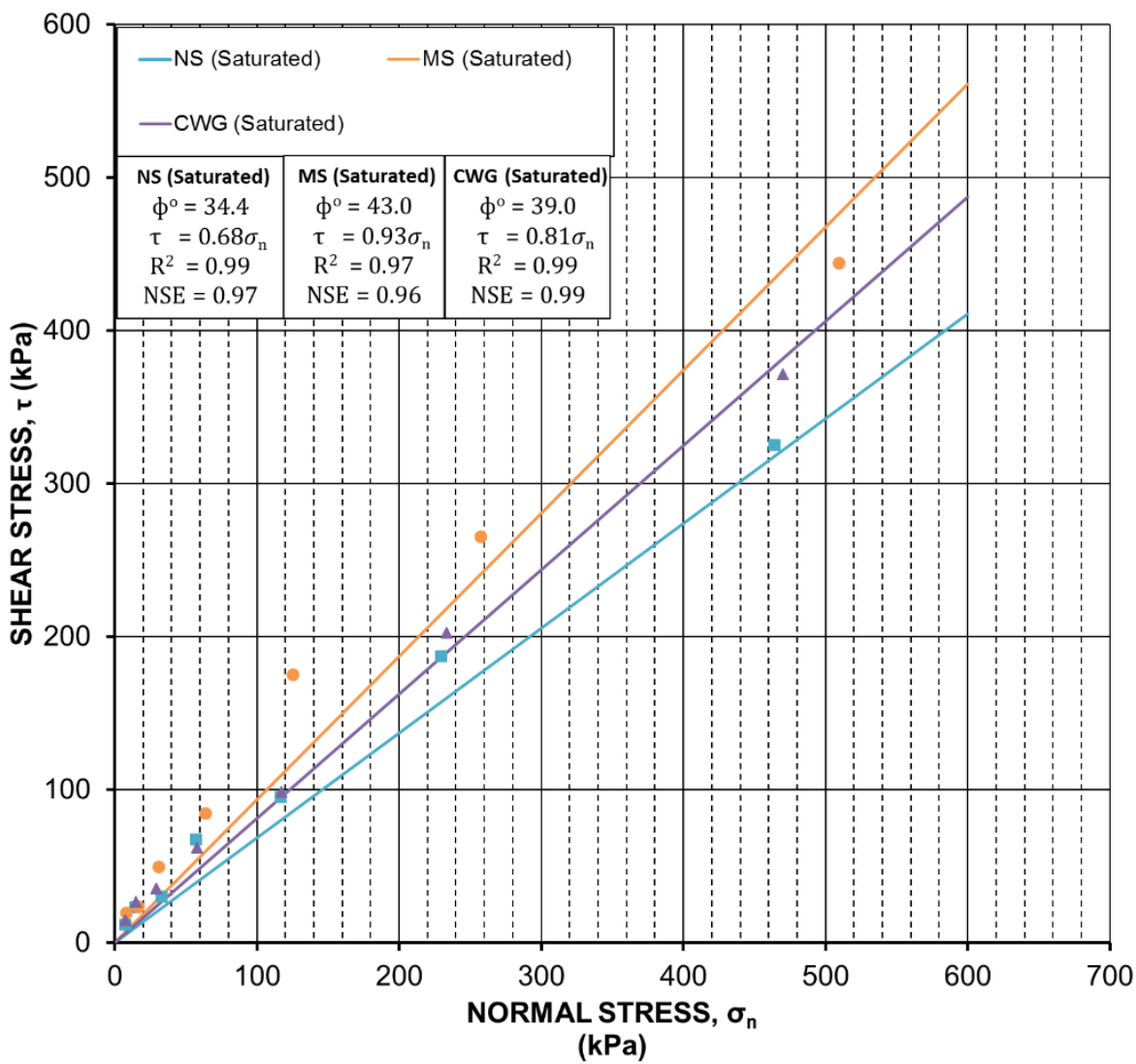
$(\mathrm{kPa})$

Fig.5. Peak shear strength envelopes of the materials under saturated conditions 


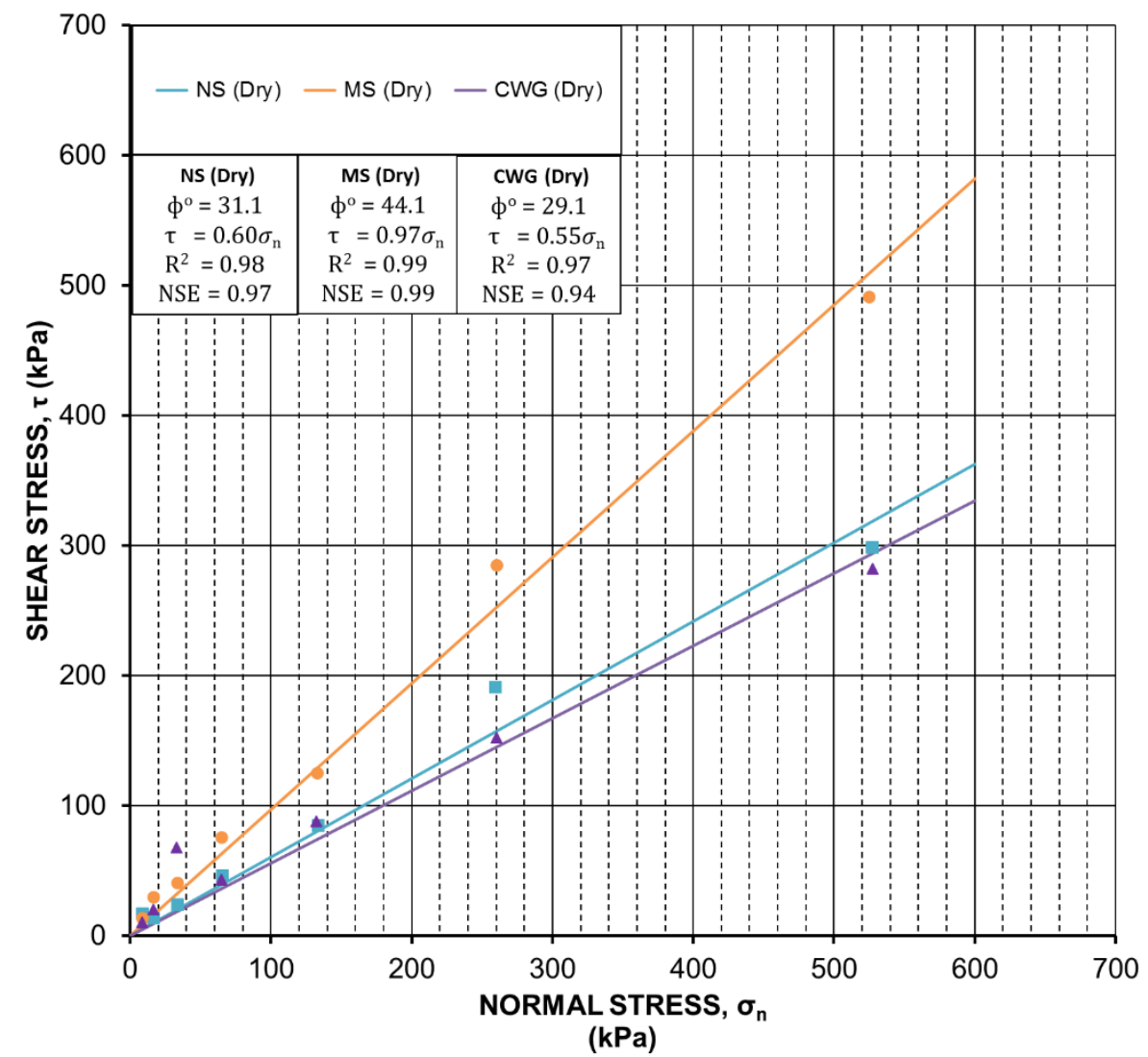

Fig.6. Final shear strength envelopes of the materials under dry conditions

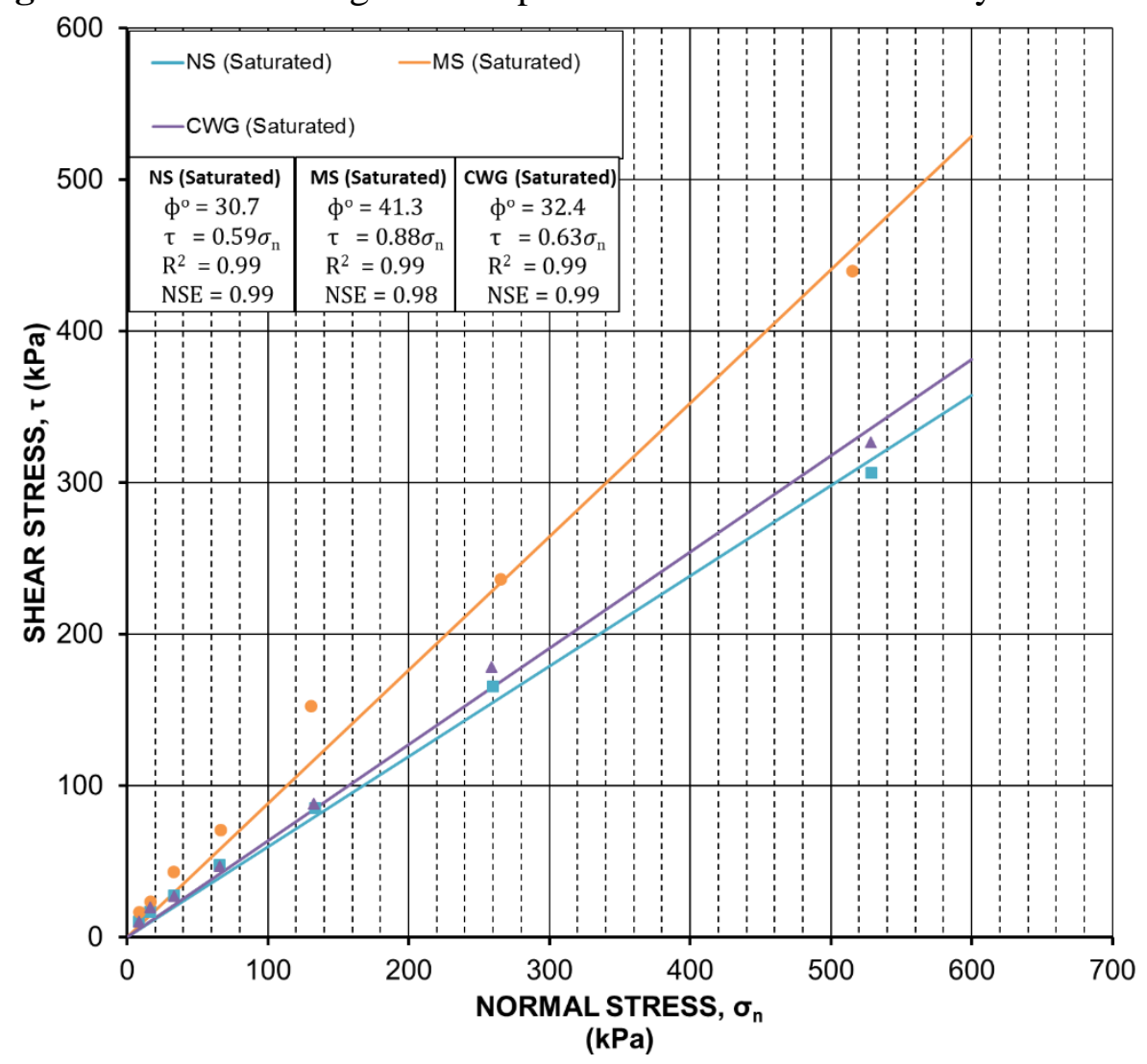

Fig.7. Final shear strength envelopes of the materials under saturated conditions 
The results of the direct shear tests under saturated conditions demonstrated a marginal decline in the peak friction angle of NS and MS; potentially due to reduced inter-particular friction caused by the introduction of water molecules between the pores of sands. The reduction of friction angle under saturated condition was expected and is consistent with previously published studies (McKelvey et al., 2002). However, interestingly, the peak and final friction angle of CWG was found to be relatively higher under saturated conditions compared to that under dry, which is contrary to typical observation in soils. The potential reason for this finding could be attributed to the adhesion between water and glass particles. When submerged in water, the surfaces of silicate glass acquire a negative surface charge density through the dissociation of terminal silanol groups Behrens \& Grier (2001), resulting in the development of adhesion between glass and water particles due to their polarity. Physically, this phenomenon could potentially be explained by considering the capillary action of water in a glass tube, leading to the formation of the meniscus. Being polar in nature, glass and water manifest adhesion at interface greater than the cohesion of individual water molecules; thus, forming a meniscus.

Figure $8 \mathrm{a}$ and $9 \mathrm{a}$ illustrate the shear strength-horizontal displacement behaviour of NS under dry and saturated conditions, respectively. Figure $8 \mathrm{~b}$ and $9 \mathrm{~b}$ represent the horizontal-vertical displacement behaviour of NS under dry and saturated conditions, respectively. The shear stress-horizontal displacement behaviour of NS in both dry and saturated conditions showed that a shear displacement of within $5.0 \mathrm{~mm}$ (shear strain of within 0.15 ) was adequate to mobilise the peak shear stress under the majority of normal loads. It was also noted that the shear stress in NS samples non-linearly increased with an increase in horizontal displacement under both dry and saturated conditions. However, the effect of normal stress on the shear stress of NS samples was relatively pronounced at higher normal stresses when a distinct peak appeared. Figure10a and 11a represent the shear strength-horizontal displacement behaviour of MS under dry and saturated conditions, respectively. Figure $10 \mathrm{~b}$ and $11 \mathrm{~b}$ represent the horizontal-vertical displacement behaviour of MS under dry and saturated conditions, respectively. The shear stress-horizontal displacement graph of MS in both dry and saturated conditions indicated that a relatively higher shear displacement, typically greater than $6 \mathrm{~mm}$, was required to mobilise peak shear stress under most of the normal stresses. Simultaneously, it was typically noted that the peak shear stress of NS was similar to its final shear stress. Figure 12a and 13a illustrate the shear strength-horizontal displacement behaviour of CWG under dry and saturated conditions, respectively. Figure $12 \mathrm{~b}$ and $13 \mathrm{~b}$ represent the horizontal-vertical displacement of CWG under dry and saturated conditions, respectively. In both dry and saturated conditions, the shear stress-horizontal displacement curve of CWG showed that a relatively lower shear displacement was required to mobilise the peak shear stress under the majority of the normal stresses. The peak shear stress mobilised at around $4.0 \mathrm{~mm}$ shear displacement, and the final vertical displacement mostly reached constant values.

Furthermore, the potential reasons for the obtained friction angles of the materials were afterwards studied using the mineralogical and morphological analysis to examine the chemical composition and particle shape of each material, respectively. 


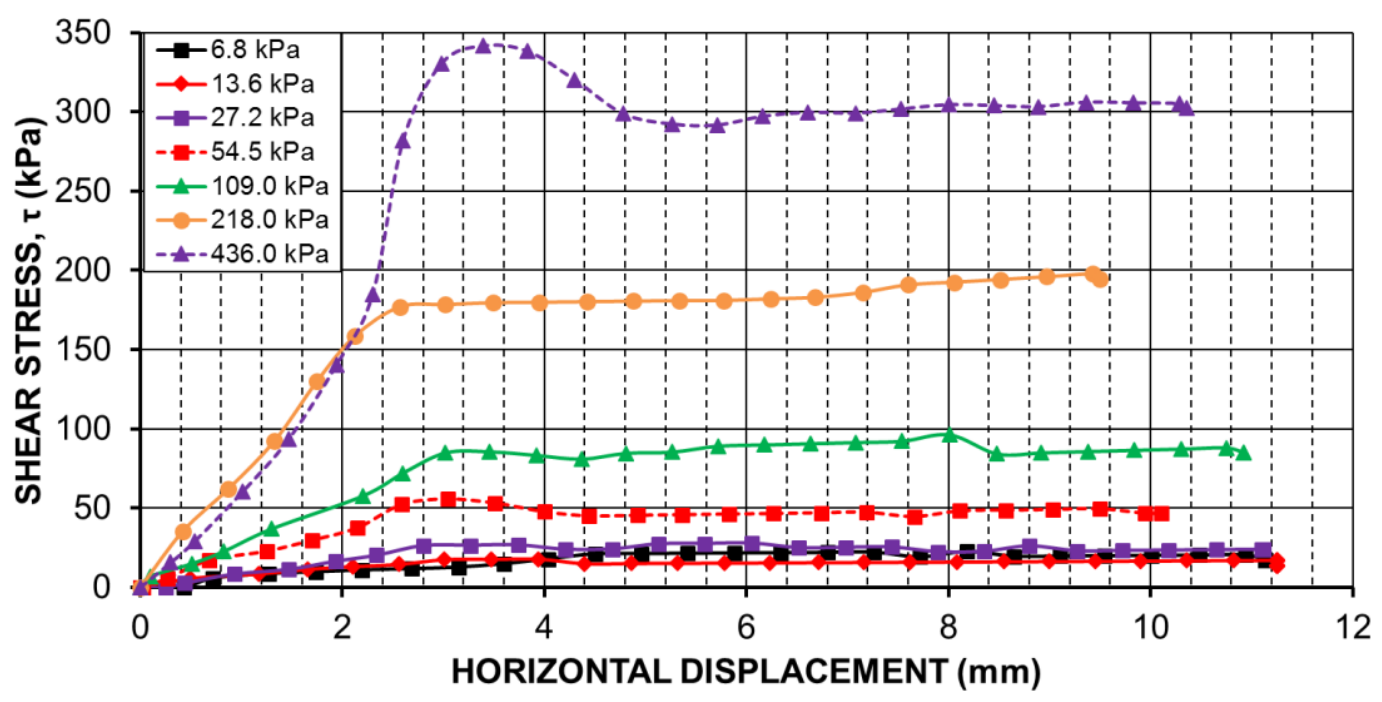

(a)

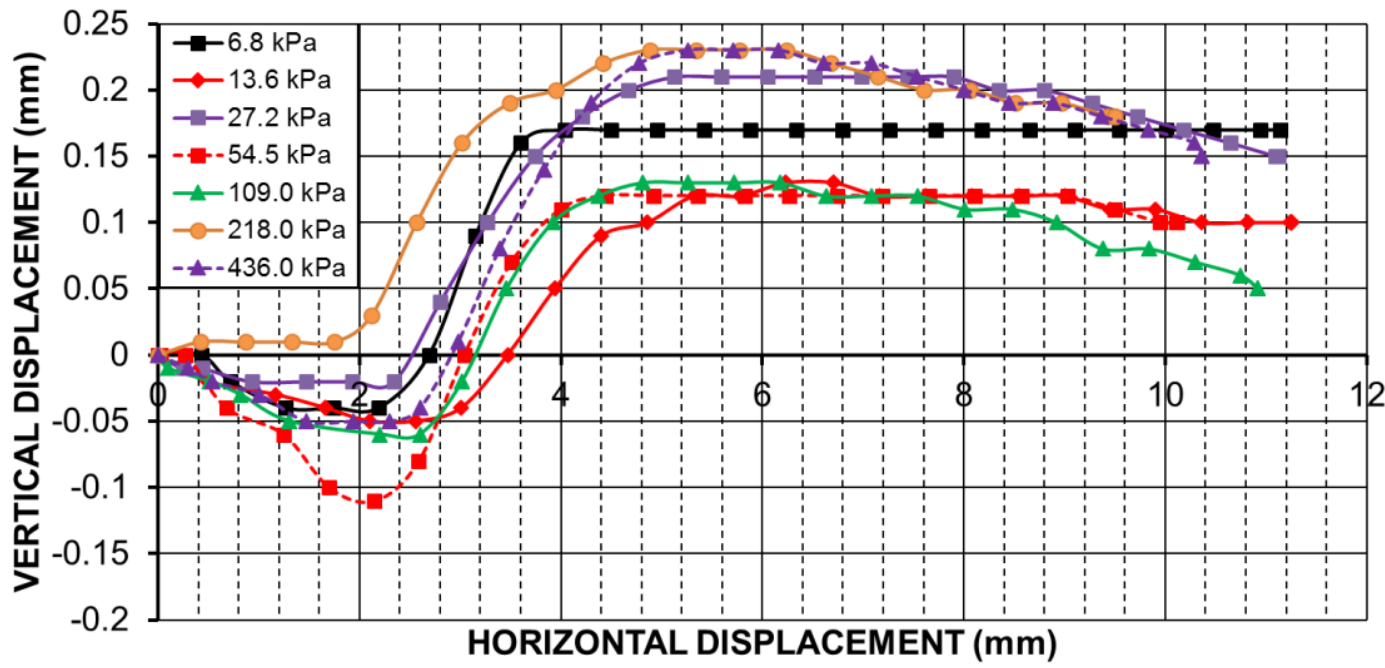

Fig. 8 (a) Shear stress-horizontal displacement behaviour of NS under dry conditions

(b) Horizontal-vertical displacement behaviour of NS under dry conditions 


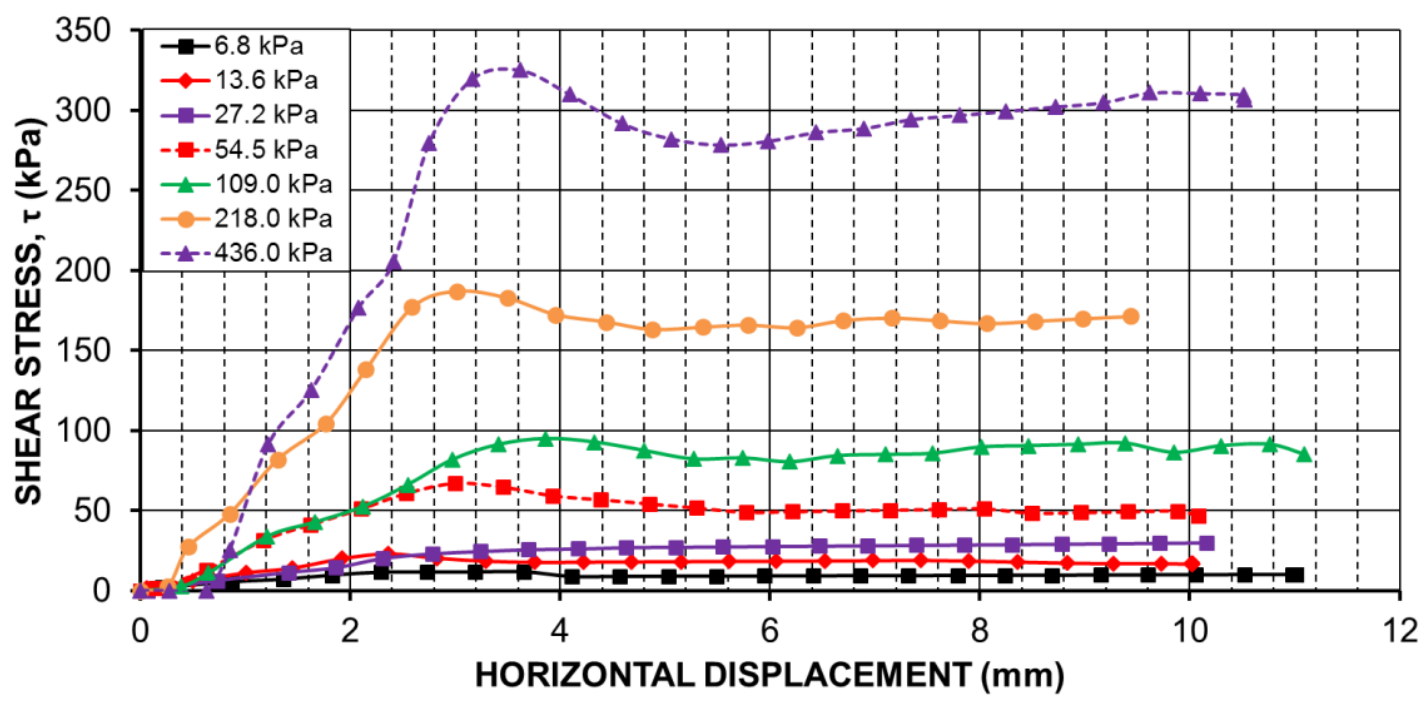

(a)

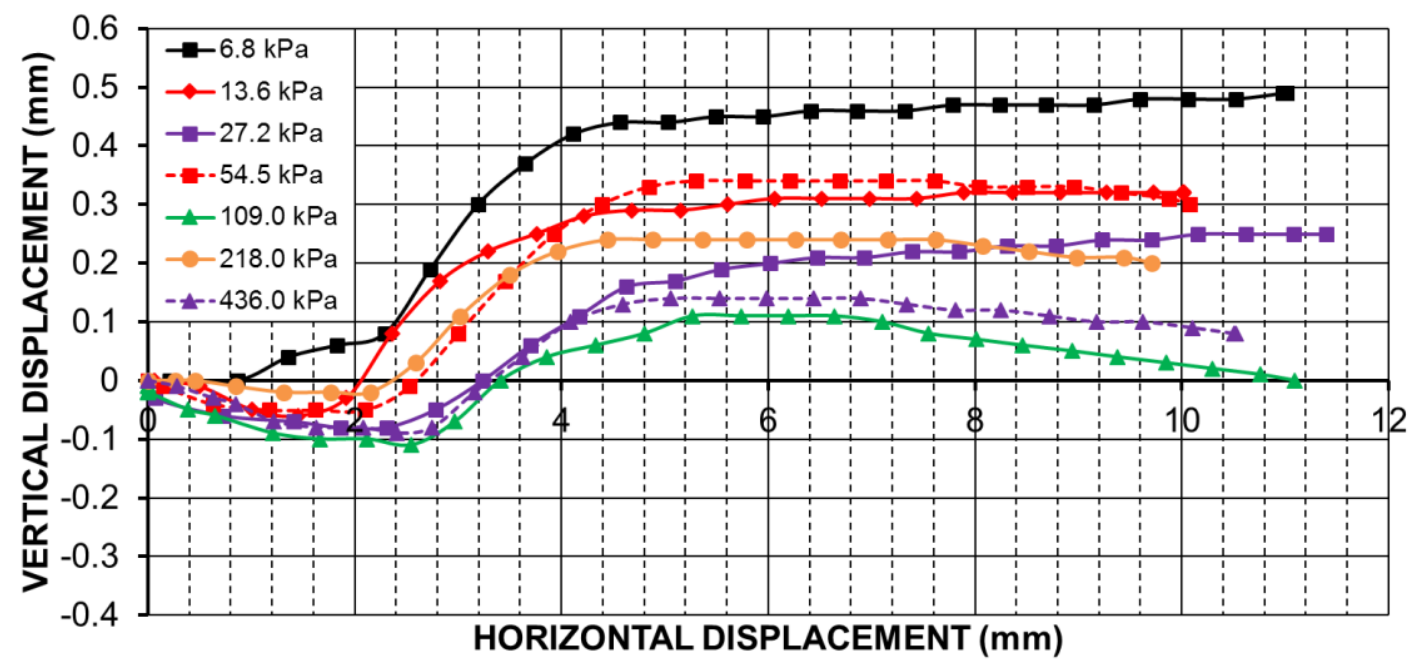

Fig.9 (a) Shear stress-horizontal displacement behaviour of NS under saturated conditions

(b) Horizontal-vertical displacement behaviour of NS under saturated conditions 


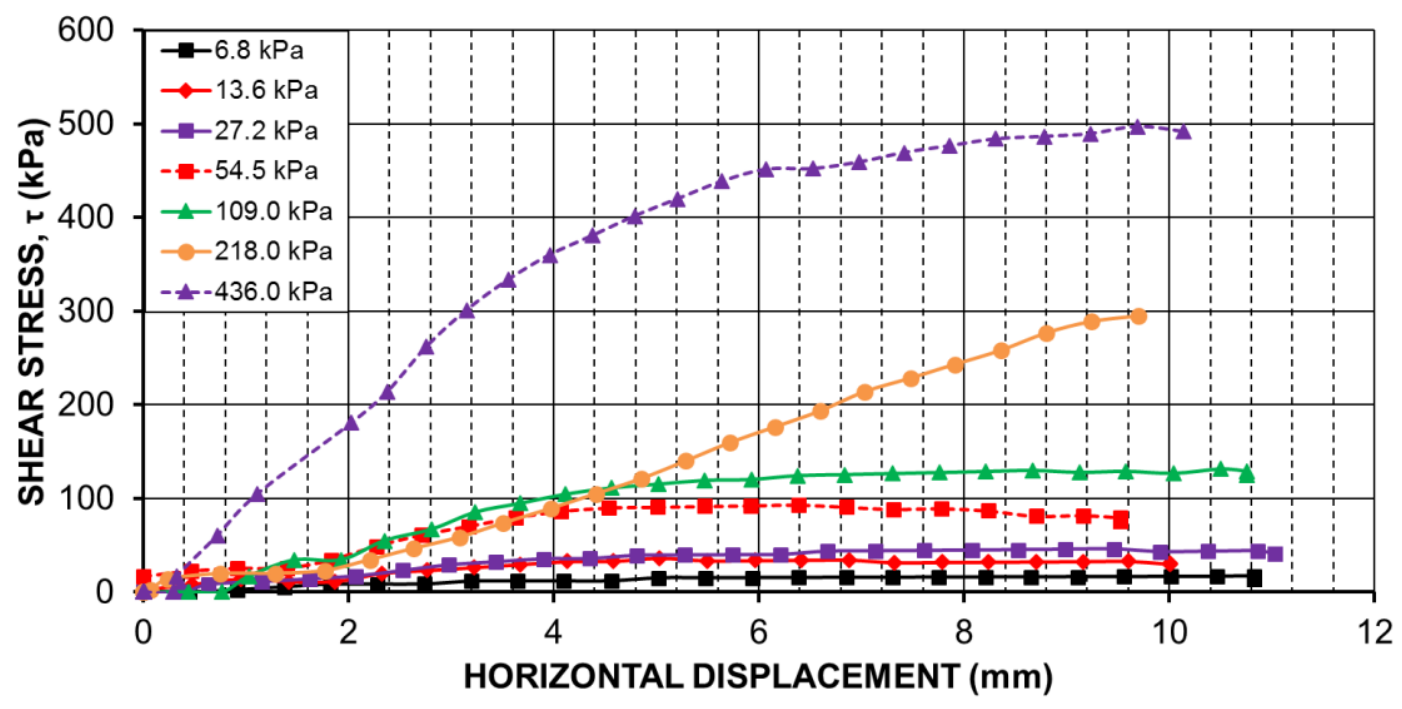

(a)

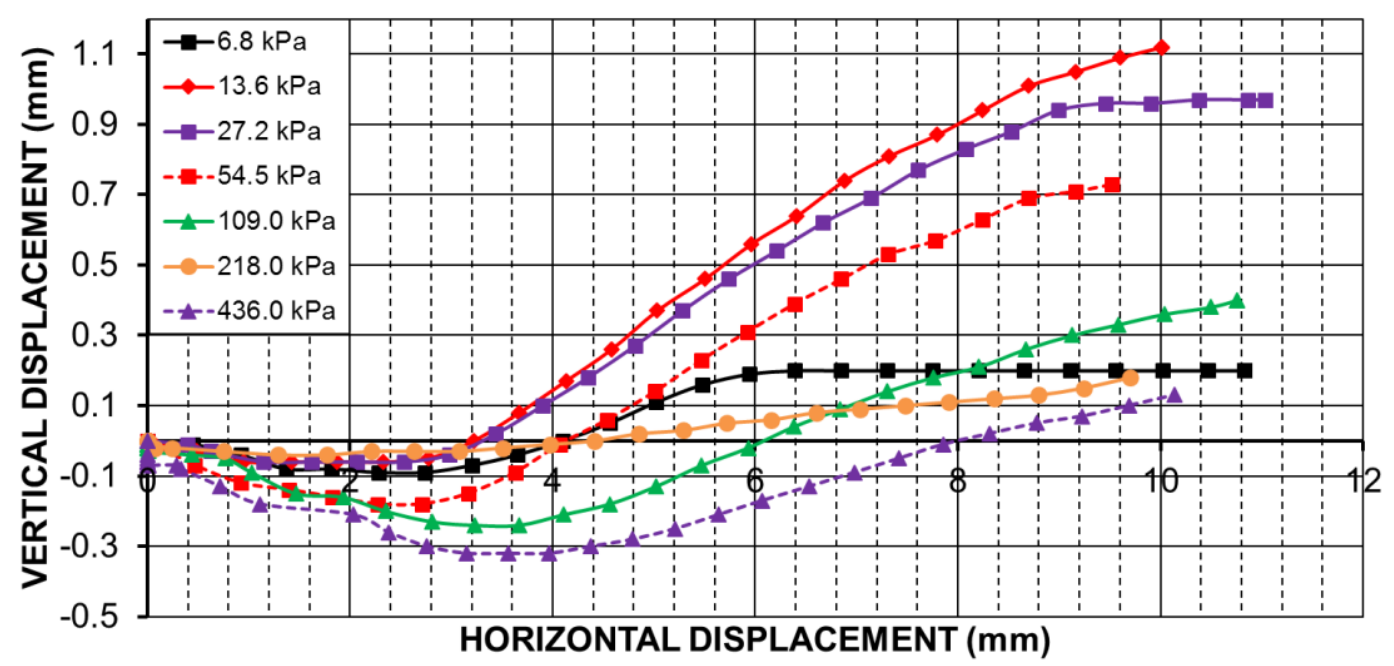

Fig.10 (a) Shear stress-horizontal displacement behaviour of MS under dry conditions

(b) Horizontal-vertical displacement behaviour of MS under dry conditions 


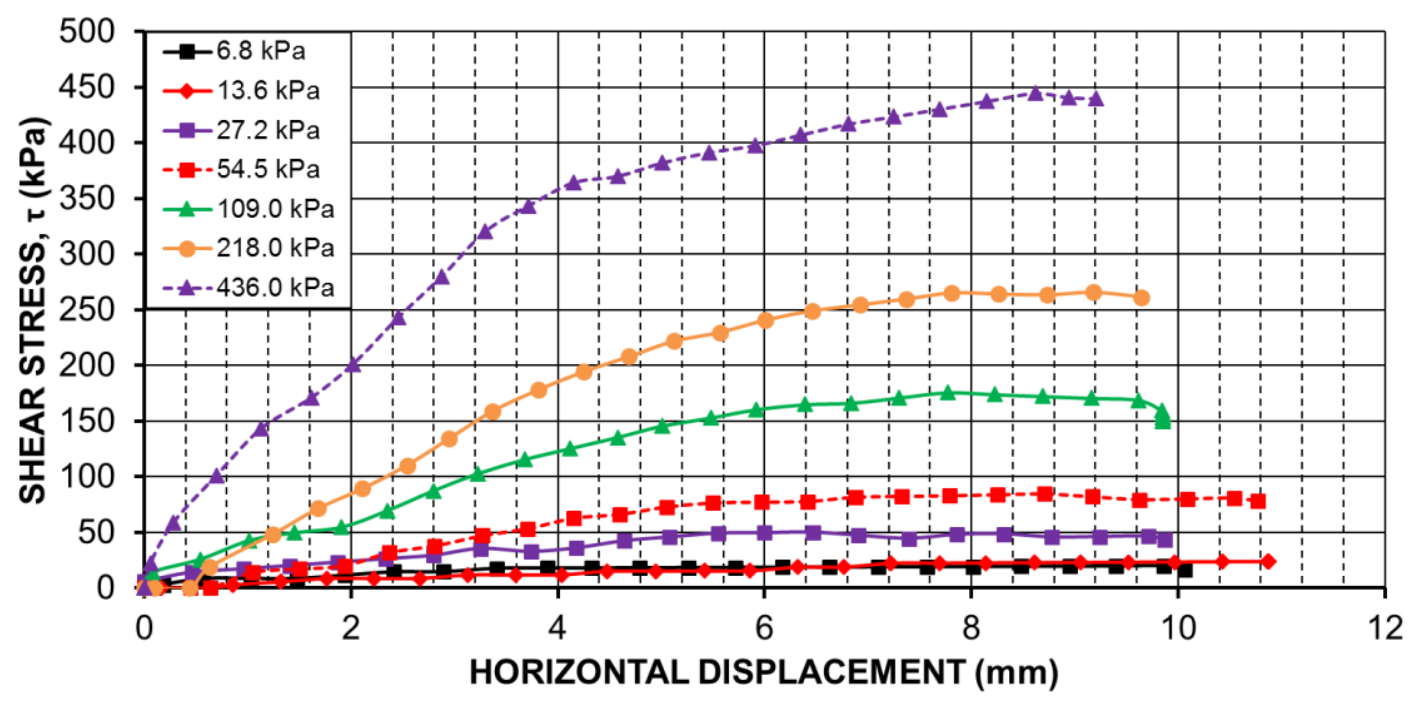

(a)

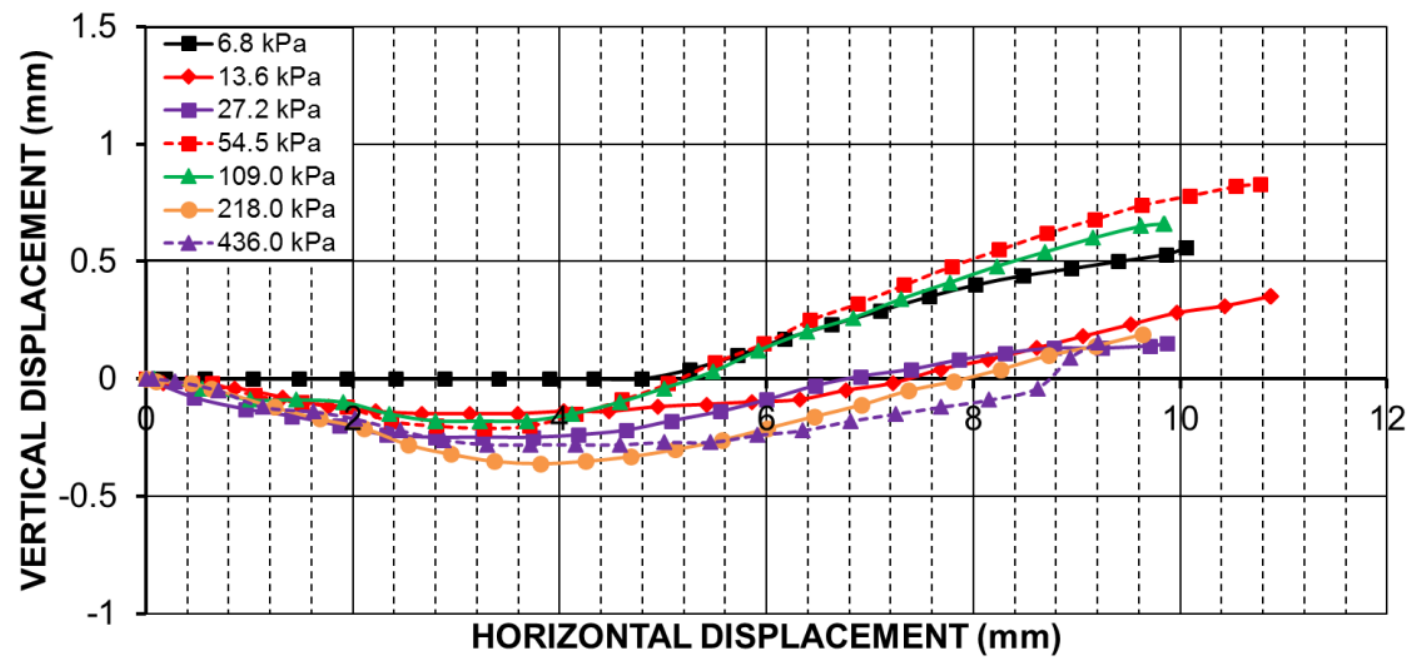

377 (b)

Fig.11 (a) Shear stress-horizontal displacement behaviour of MS under saturated conditions (b) Horizontal-vertical displacement behaviour of MS under saturated conditions 


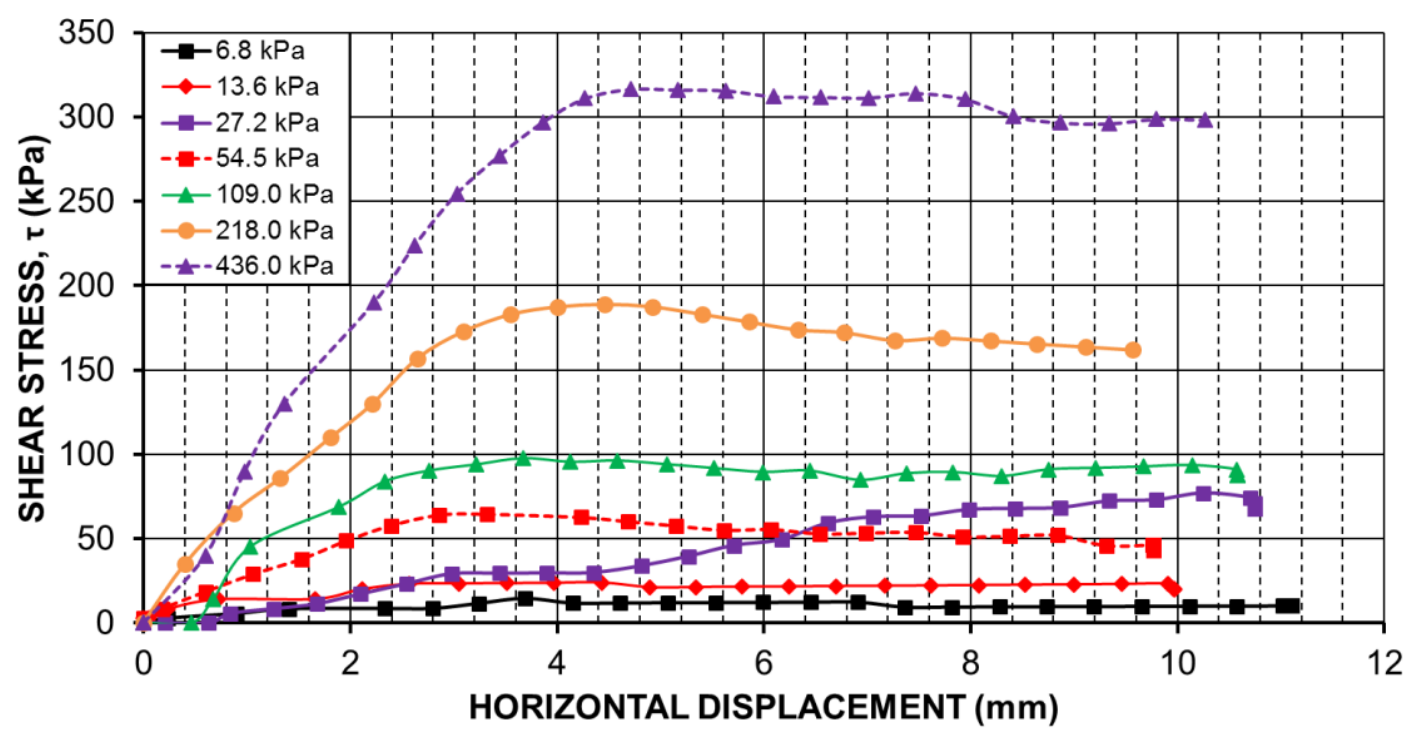

(a)

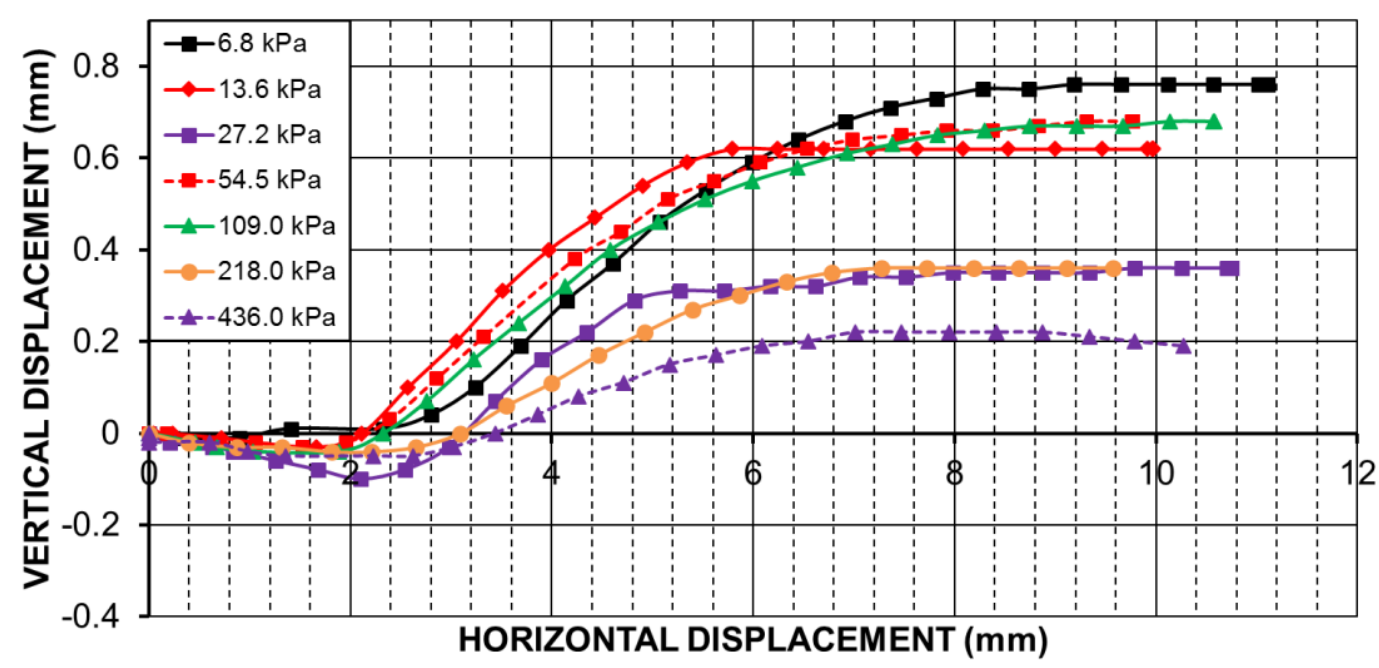

Fig.12 (a) Shear stress-horizontal displacement behaviour of CWG under dry conditions

(b) Horizontal-vertical displacement behaviour of CWG under dry conditions 


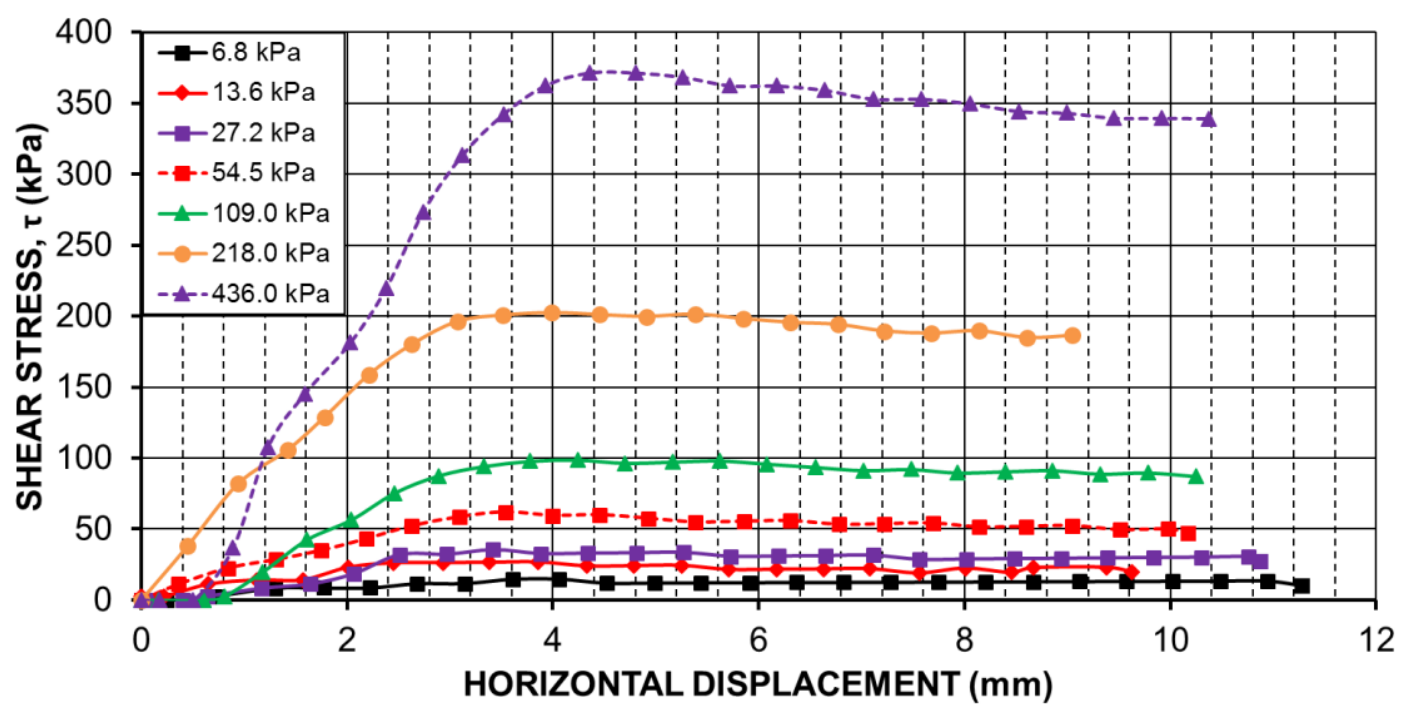

391

392

(a)

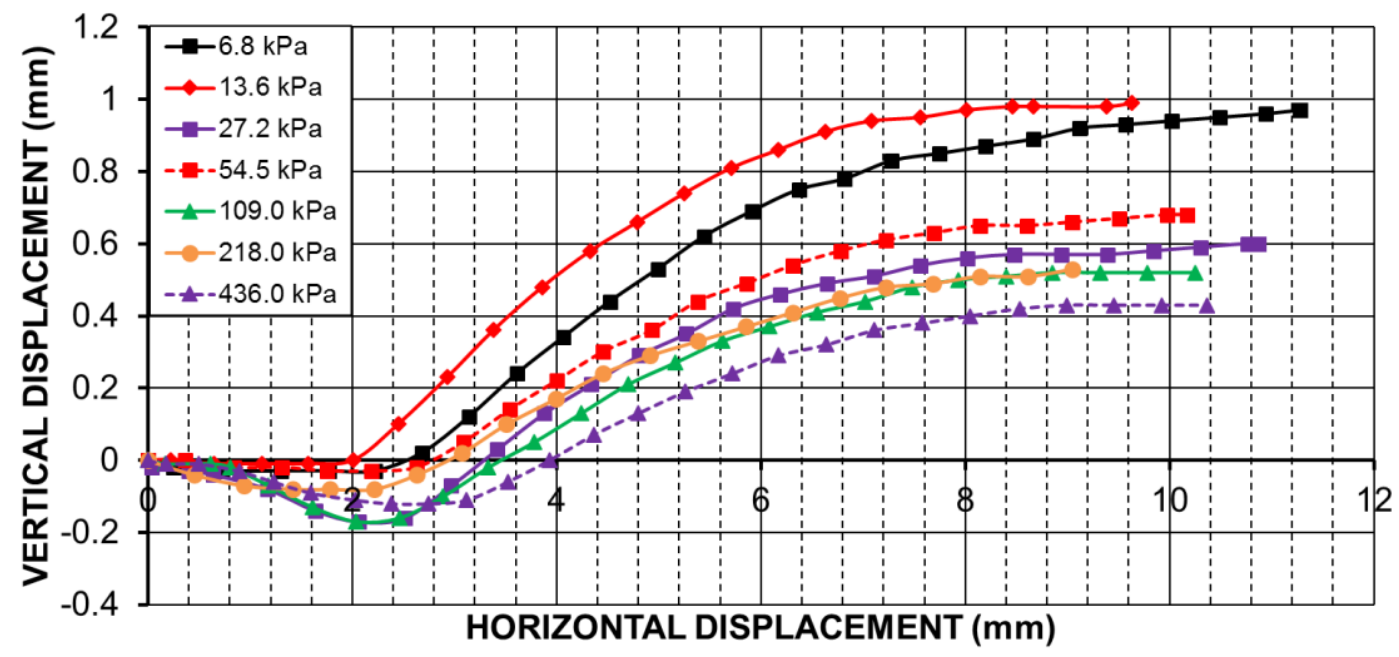

(b)

Fig.13 (a) Shear stress-horizontal displacement behaviour of CWG under saturated conditions (b) Horizontal-vertical displacement behaviour of CWG under saturated conditions

\subsection{X-ray fluorescence spectroscopy for the mineralogical analysis}

The mineralogical analysis of the materials was conducted to determine their elemental composition, particularly the silica $\left(\mathrm{SiO}_{2}\right)$ content. Silica is the second-most abundant mineral found on Earth (Patel \& Vashi, 2015). Typically, silica comes in the form of quartz and serves as the most common mineral component of sand, offering higher crushing resistance (Altuhafi et al., 2016). Silica is a hard and chemically inert mineral exhibiting a high melting point (Durowaye et al., 2017). Besides performing the mineralogical characterisation, a key motivation to perform the elemental analysis was to explore the similarity in the chemical composition of NS, MS and CWG. The results of XRF spectroscopy demonstrated that silica is the primary mineral in all three materials, with the highest concentration present in NS (99.81\%) followed by CWG (72.07\%) and MS (67.74\%). These XRF spectroscopy results show that CWG has a chemical composition comparable to traditional sands (see Table 4). 
Table 4. Mineralogical analysis of materials performed using XRF spectroscopy.

\begin{tabular}{|c|c|c|c|c|}
\hline Oxide concentration & Units & NS & MS & CWG \\
\hline $\mathrm{SiO}_{2}$ & $\%$ & 99.81 & 67.74 & 72.07 \\
\hline $\mathrm{TiO}_{2}$ & $\%$ & 0.06 & 0.67 & 0.05 \\
\hline $\mathrm{Al}_{2} \mathrm{O}_{3}$ & $\%$ & $<0.01$ & 16.17 & 1.45 \\
\hline $\mathrm{Fe}_{2} \mathrm{O}_{3}$ & $\%$ & 0.05 & 5.81 & 0.34 \\
\hline $\mathrm{MnO}$ & $\%$ & $<0.01$ & 0.12 & 0.01 \\
\hline $\mathrm{MgO}$ & $\%$ & 0.03 & 2.13 & 0.69 \\
\hline $\mathrm{CaO}$ & $\%$ & 0.01 & 1.38 & 11.09 \\
\hline $\mathrm{Na}_{2} \mathrm{O}$ & $\%$ & $<0.01$ & 1.71 & 13.73 \\
\hline $\mathrm{K}_{2} \mathrm{O}$ & $\%$ & 0.01 & 3.72 & 0.33 \\
\hline $\mathrm{P}_{2} \mathrm{O}_{5}$ & $\%$ & 0.01 & 0.16 & 0.03 \\
\hline $\mathrm{SO} \mathrm{S}_{3}$ & $\%$ & 0.01 & 0.24 & 0.09 \\
\hline $\mathrm{V}_{2} \mathrm{O}_{5}$ & $\mathrm{ppm}$ & 9 & 177 & 20 \\
\hline $\mathrm{Cr}_{2} \mathrm{O}_{3}$ & $\mathrm{ppm}$ & 11 & 97 & 539 \\
\hline $\mathrm{ZnO}$ & $\mathrm{ppm}$ & 5 & 122 & 72 \\
\hline $\mathrm{SrO}_{\mathrm{BaO}}$ & $\mathrm{ppm}$ & 2 & 133 & 155 \\
\hline $\mathrm{Co} \mathrm{O}_{4}$ & $\mathrm{ppm}$ & 26 & 920 & 355 \\
\hline $\mathrm{NiO}$ & $\mathrm{ppm}$ & 42 & 18 & 26 \\
\hline $\mathrm{CuO}$ & $\mathrm{ppm}$ & 8 & 42 & 4 \\
\hline & & $<2$ & 37 & 4 \\
\hline
\end{tabular}

$410 \quad 4.3$ Microscopic analysis for particle shape quantification

411 Figure 14, 15 and 16 show the optical microscopy (OM) images containing particles of NS, 412 MS and CWG, respectively. The statistical results obtained using CLT showed that, as the sample size became larger, the distribution of sample means for all three materials approached a normal distribution, which is consistent with the theory of CLT. The skewness and kurtosis of data were calculated to choose the most representative value of particles' roundness index. As the skewness for a perfectly normal distribution is 0 , it was seen that the skewness of sample means distribution for all three materials progressively decreased with an increasing number of particles per sample. The acceptable range of skewness for normal distribution lies between -1 to +1 (Chan, 2003). For all given materials, it was noted that the skewness of sample mean distribution was relatively closer to 0 in samples with 25 particles each; potentially indicating a normal distribution. The chi-square goodness of fit test was used to test whether the data with 25 particles come from a normal distribution. The p-value was found to be much larger than the conventional significance level of 0.05 , so the null hypothesis was retained that the data is normally distributed. Thus, the mean roundness index corresponding to a sample size of 25 particles per sample was selected for all three materials. Figure 17, 18 and 19 represents the frequency distribution of sample means for roundness index of NS, MS and CWG, respectively. Table 5 represents the statistical results obtained using CLT. 
428

429

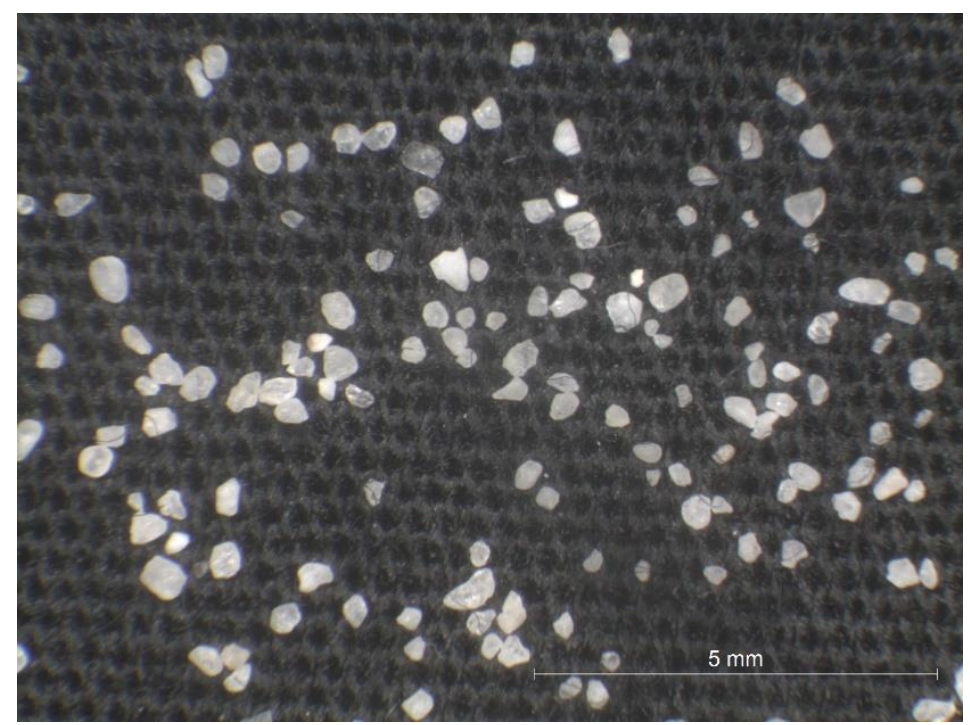

Fig.14. Micrograph of NS particles

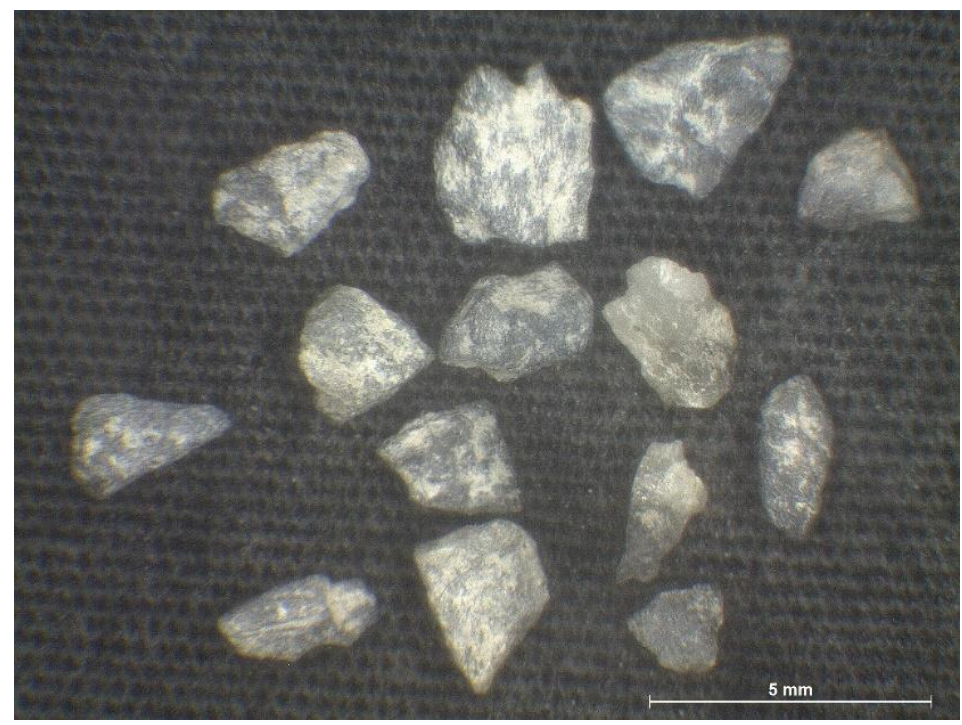

Fig.15. Micrograph of MS particles

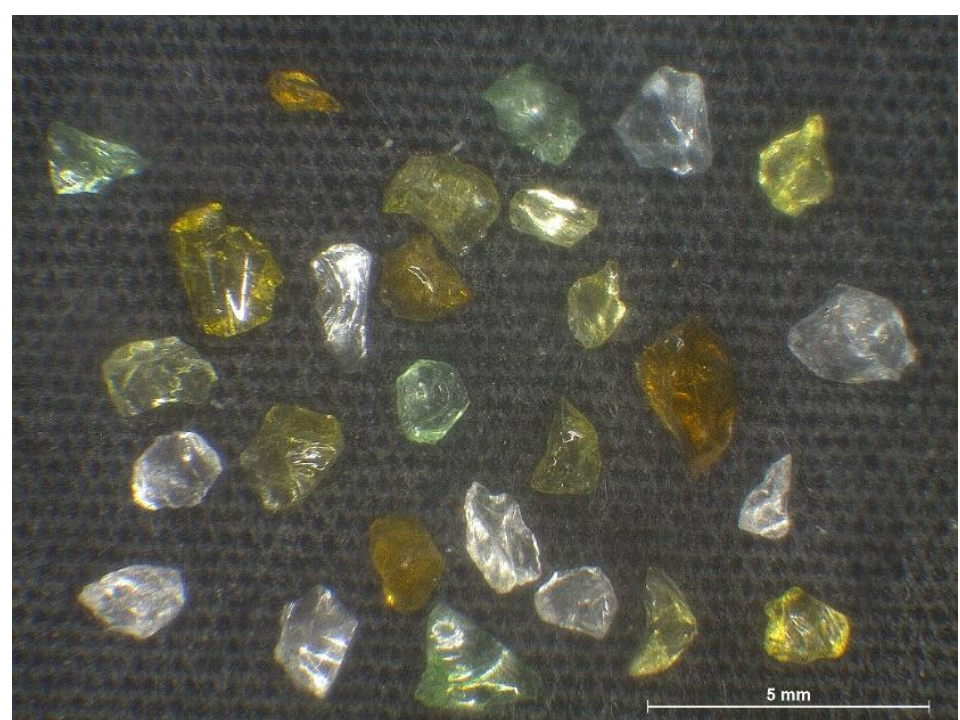

Fig.16. Micrograph of CWG particles 


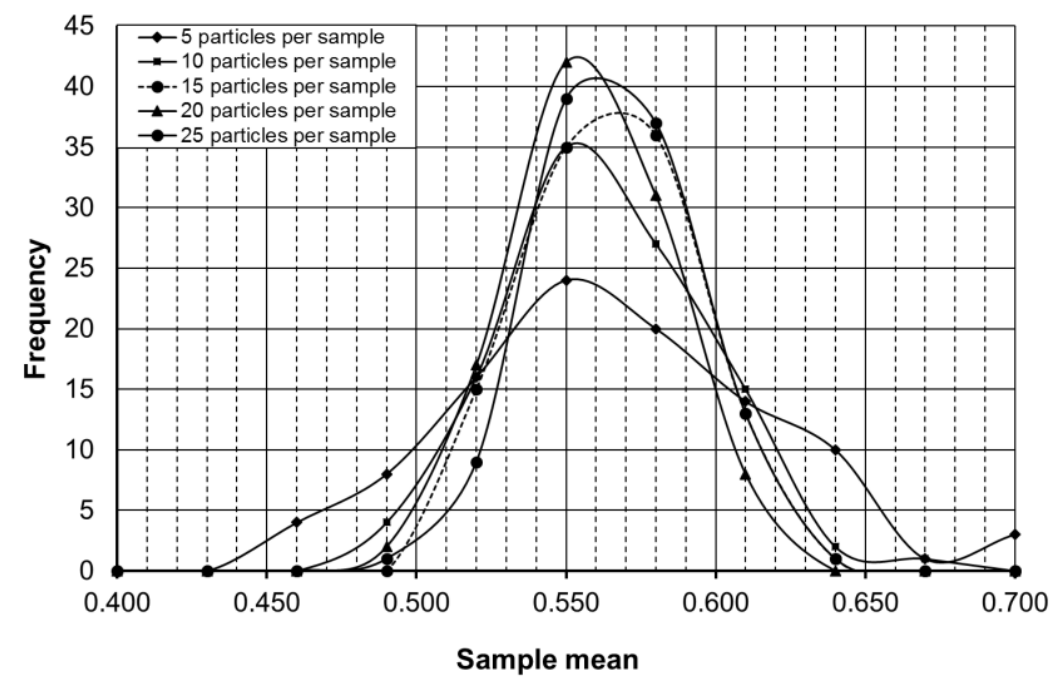

Fig. 17. Frequency distribution curve for the roundness index of NS

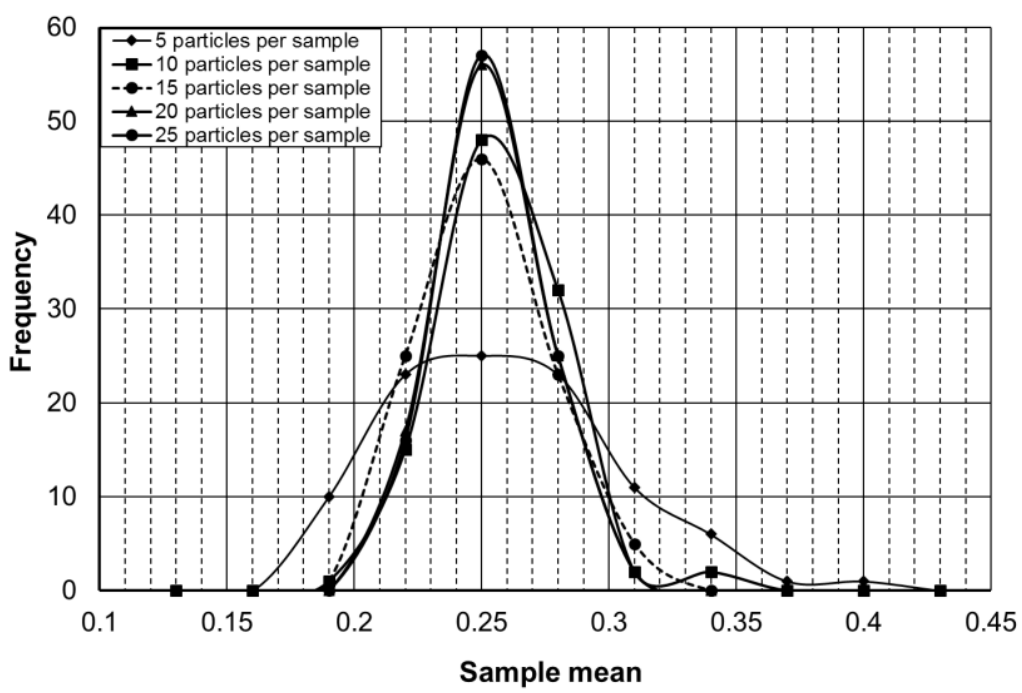

Fig. 18. Frequency distribution curve for the roundness index of MS

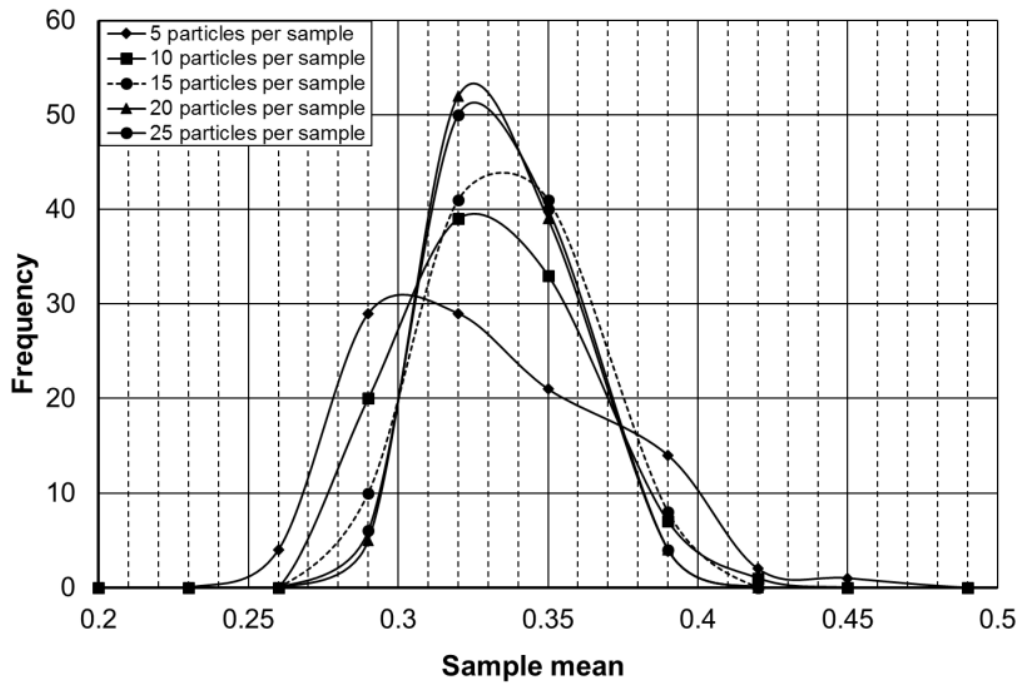

Fig. 19. Frequency distribution curve for the roundness index of CWG 
Table 5. Statistical results obtained using CLT

\begin{tabular}{|c|c|c|c|c|c|c|}
\hline \multirow{2}{*}{$\begin{array}{c}\text { No of particles per } \\
\text { sample }\end{array}$} & \multicolumn{2}{|c|}{ NS } & \multicolumn{2}{c|}{ MS } & \multicolumn{2}{c|}{ CWG } \\
\cline { 2 - 7 } & Skewness & Kurtosis & Skewness & Kurtosis & Skewness & Kurtosis \\
\hline 5 & 0.342 & -0.187 & 0.638 & 0.354 & 0.678 & 0.571 \\
\hline 10 & 0.262 & 0.031 & 0.479 & 0.803 & 0.470 & 0.844 \\
\hline 15 & 0.110 & -0.500 & 0.396 & -0.162 & 0.236 & -0.083 \\
\hline 20 & 0.045 & -0.356 & 0.249 & 0.151 & 0.058 & -0.137 \\
\hline 25 & -0.006 & 0.116 & 0.086 & -0.254 & 0.036 & -0.378 \\
\hline
\end{tabular}

441

442

443

The results of the morphological analysis showed that MS has the highest particle angularity, with a roundness index of 0.24 , followed by CWG and NS. Table 6 represents the roundness index of the three materials.

Table 6. Roundness indices of materials calculated using morphological analysis

\begin{tabular}{|c|c|c|c|}
\hline Material & NS & MS & CWG \\
\hline Roundness index & 0.55 & 0.24 & 0.32 \\
\hline
\end{tabular}

\section{Discussion}

The geotechnical characterisation tests demonstrated that CWG exhibits a behaviour similar to NS and MS at given particle size and gradation. It was observed that the specific gravity of CWG was close to that of the other two sands. The potential reason for this finding could be a similarity in the chemical composition of all three materials, noting that silica is the dominant mineral in all three materials, as evidenced by the mineralogical analysis. Glass is typically a derivative of natural sand, meaning $\mathrm{CWG}$ is expected to show a chemical composition comparable to traditional sands. Likewise, the densities of all three materials were found to be comparable to each other. The potential reason for a relatively higher maximum dry density of MS could be the well-graded gradation and higher particle angularity, as demonstrated by the gradation and morphological analysis, respectively. Since NS is a uniformly graded material, exhibiting relatively higher particle roundness, its maximum dry density turned out to be the lowest of all three materials studied. Importantly, it was observed that CWG outperformed the other two sands in hydraulic conductivity and abrasion testing. It was noted that the hydraulic conductivity of CWG was highest among all three materials; indicating a potential to offer favourable drainage behaviour in various geotechnical applications. This point is also endorsed by the findings of previous studies, favouring the use of CWG as a drainage media in various applications, such as retaining walls, footing drains, French drains and drainage blanket (Wartman et al., 2004). The potential reason for a higher permeability of CWG is the nonporous and smooth surfaces of its particles which do not hold moisture alongside a lack of claysized particles in the recycled glass mixtures (Clean Washington Center, 1998).

The abrasion testing showed that the abrasion resistance of CWG was nearly two and four times superior to NS and MS, respectively. The relatively superior abrasion resistance of CWG could be particularly beneficial to applications where the materials are subjected to impact, potentially increasing the structural durability due to reduced wear and tear. Besides technical benefits, the higher abrasion resistance of CWG could be helpful during the logistics, such as transportation, handling and installation.

The shear strength testing of materials showed that the friction angle of CWG is comparable to traditional sands. It was found that MS has the highest peak friction angle under saturated conditions, followed by CWG and NS. Typically, the friction angle of sands is relatively lower under saturated conditions than under dry conditions, due a to greater inter-particle lubrication. 
However, surprisingly, it was observed that the friction angle of CWG was considerably higher under saturated conditions than under dry conditions, showing an increase of nearly $10 \%$, potentially due to a greater adhesion between water and CWG particles. This increase in the saturated friction angle of CWG could be favourable for applications where the moisture content is high and keep fluctuating. Since the peak and final friction angle of MS was found to be the highest of all three materials, the potential reasons for this finding could be the wellgraded gradation, relatively large mean particle size and higher particle angularity of MS.

Morphologically, digital image analysis was performed to analyse the particle shape of the materials using an optical microscope. Particle shape is an essential parameter in the fields of civil engineering and geology due to its significant impact on the physical behaviour of soils (Lees, 1964). Several researchers have attempted to develop descriptors to quantify the shape of particles, including the normalised shape factor (SF) proposed by Sukumaran \& Ashmawy (2001), the fractal dimension proposed by Vallejo \& Zhou (1995) and the ruggedness factor proposed by Wettimuny \& Penumadu (2004). However, due to a long history and consistent use, the most accepted method for particle shape quantification was developed by Wadell in 1932 (Zheng \& Hryciw, 2016). Wadell (1932) used the term roundness and defined it as the mean radius of curvature of surface features relative to the radius of the largest sphere that can be inscribed in the grain. Roundness is typically sensitive to the sharpness of angular protrusions from the grain; yielding higher values for smooth grains and lower values for the rough ones (Bowman et al., 2001). Figure 20 exemplifies the roundness of a particle in terms of angular protrusions. Studies show that the angularity, which denotes variations at the corners of particles, plays a pivotal role in promoting interlocking between particles (Hossain et al., 2007; Zhao et al., 2015). Holubec \& D'appolonia (1973) tested the effect of particle shape on the geotechnical engineering parameters of granular soils and concluded that granular materials with the same relative density could manifest significantly different behaviour due to variation in particle angularity. Some studies show that particle breakage is often guided by particle angularity (shape) rather than size (Lackenby, 2006). Qing-bing et al. (2011) studied the effect of particle shape on the shear strength behaviour of three different sands. Their study found that the critical friction angle of sand reduces linearly with an increase in particle roundness. Similarly, Shinohara et al. (2000) showed a direct relationship between particle angularity and friction angle, suggesting that angular particles offer greater interlock than rounded ones.

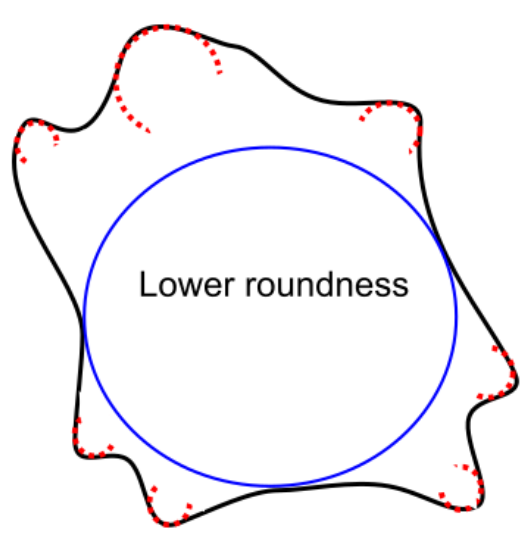

Higher angular protrusions

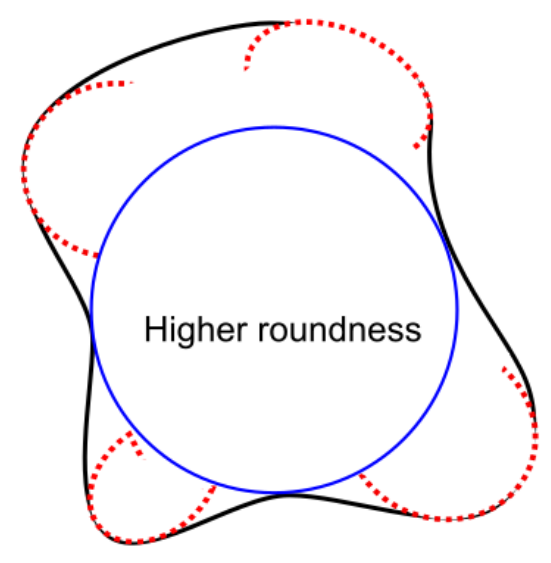

Lower angular protrusions

Fig. 20. Effect of angular protrusions on the roundness of the particle (adapted from Hawkins, 1993)

510 The results of the morphological analysis showed that MS has the highest particle angularity, 511 followed by CWG and NS. Typically, the particle shape of materials is not analysed 
quantitatively for geotechnical applications. However, the results of a few studies show that angular sands tend to exhibit a larger friction angle, higher maximum and minimum void ratios, and greater compressibility potential, compared to their rounded counterparts under similar conditions (Muszynski \& Vitton, 2012). It was observed that the particle angularity of CWG was markedly higher than that of NS and relatively closer to that of MS. In other civil engineering applications, such as concrete, the higher angularity of aggregates is not always desirable, as it could reduce the workability of fresh concrete. However, the relatively higher particle angularity of CWG could directly help improve the structural stability in numerous geotechnical applications; favouring the potential use of $\mathrm{CWG}$ as an alternative geomaterial.

The calculated roundness indices were classified using particle roundness grades as suggested by Russell \& Taylor (1937), classifying particles into five distinct classes of shape using the roundness estimates of Wadell (1932). It was found that NS has a rounded particle shape, whereas MS turned out to be sub-angular. The particle shape of CWG was found to be subrounded. These results are comparable to the findings of some previous studies reporting the roundness indices of different sands. For example, Cho et al. (2006) calculated the roundness index of various natural sands. Their study found that the roundness index of Nevada and sandboil sand was found to be 0.60 and 0.55 respectively, which is similar to the roundness index of NS, 0.55 , obtained in this study.

Interestingly, it was noted that the roundness indices of CWG and MS were relatively closer to each other, with a difference of nearly $28 \%$, indicating a relatively higher particle angularity in both materials. These results are consistent with the findings of some previous studies, suggesting that natural sands tend to have rounded shape, whereas manufactured sands have angular particles (Kumar, 2016). Since the natural sand was sourced from a beach, it was expected to contain rounded grains, as roundness is predominantly caused by abrasion during sediment transport (Nichols, 2009). Likewise, some previous studies confirmed that manufactured sands have relatively higher particle angularity Chetia et al. (2017); potentially due to relatively lower exposure to abrasion compared to natural sands, which are subjected to erosion due to wave and aeolian action. Since CWG is obtained by crushing and processing of waste glass, the particle shape of CWG is expected to be relatively angular (So et al., 2016). This study found that the particle shape of CWG is sub-rounded, lying midway between that of NS and MS. Considering the brittle nature of CWG, a potential reason for its sub-rounded classification could be the particle breakage due to attrition, causing a change in shape from angular to sub-rounded particles (Dhir et al., 2018).

Despite the findings described above, it is vital to consider the effect of particle size on the geotechnical performance of granular materials. Several previous studies have shown that wellgraded sands with large particles tend to exhibit relatively greater shear strength. Bareither et al. (2008) investigated the effects of physical characteristics on the shear strength of different compacted sands. Their study observed that well-graded sands with large particles showed the highest friction angles. Islam et al. (2019) examined the impact of particle size on the shear strength behaviour of sands using a direct shear machine. Their study found that the friction angle increased with increase in particle size for well-graded sands. Similarly, Dai et al. (2016) analysed the effect of particle size on the friction angle of different uniformly-graded glass beads. Their study reported that the peak friction angle of glass beads increased and showed a more dilative shearing response with increasing mean particle size $\left(\mathrm{D}_{50}\right)$, concluding that particle size may influence the shear strength behaviour of granular materials. However, these findings for granular materials may not necessarily correspond to CWG. Disfani et al. (2011b) analysed the geotechnical behaviour of three types of CWG, categorised based on their maximum particle size, which was $4.75,9.5$ and $19 \mathrm{~mm}$. Their study observed that the geotechnical behaviour of CWG deteriorates at coarser particle size because of several reasons, 
including its low ability to hold and absorb water, substantial changes in gradation curves pre and post-compaction, and relatively higher segregation potential. It was concluded that CWG with coarse particles reduces its potential for use in geotechnical engineering applications. However, the same study reported that CWG with fine and medium-sized particles offered superior geotechnical behaviour, comparable to traditional sand, and could potentially be used in a range of geotechnical applications.

Currently, the use of CWG in traditional geotechnical applications is relatively underresearched (Kazmi et al., 2019b). Secondly, there are presently limited suppliers of CWG in Australia offering CWG for recycling applications. Once the geotechnical applications of CWG are fully developed, its acceptance and availability would be expected to increase, and its price would be expected to drop due to increased market competition. Presently, the major barrier to the use of CWG in geotechnical engineering projects is a lack of knowledge on its geotechnical behaviour Disfani et al. (2011b); potentially indicating a research gap. Greater use of CWG would help the recycling companies dispose of thousands of tonnes of waste glass that is currently being sent to landfills or stockpiled. Lastly, due to the environment-friendly nature and growing focus on sustainability, the secondary use of CWG is expected to gain greater acceptance.

Despite huge potential, no formal study has been found exploring the use of CWG as backfill in stone column construction (Zukri \& Nazir, 2018). Therefore, in continuation to this research and for the first time, a separate study will be presented in future to examine the geotechnical behaviour of CWG as a next-generation alternative to traditional sands for use as a column backfill in granular pile construction. Technically, the next stage of this research will involve investigating the geotechnical performance of "glass column", made with CWG and installed in weak soil, as opposed to the traditional sand/stone columns used for ground improvement. Presumably, the challenges typically associated with the use of CWG in concrete, such as alkali-silica reaction and workability issues, will not dominate if CWG is used to backfill ground columns; potentially replacing traditional sand in a typical geotechnical application.

\section{Conclusion}

This study compared the geotechnical, mineralogical and morphological behaviour of CWG with that of NS and MS. Overall, it was observed that the behaviour of CWG is similar, or sometimes even superior, to traditional construction sands at given particle size and gradation. The geotechnical characterisation tests showed that CWG has similar behaviour to NS and MS, with CWG exhibiting superior permeability and abrasion resistance. Potential reasons for a comparable geotechnical behaviour of CWG and traditional sands could be their similar chemical composition and specific gravity, alongside the relatively angular particle shape of CWG. Moreover, as opposed to the typical observation, the shear strength testing showed that the friction angle of CWG increased under saturated conditions compared to that under dry; potentially showing its stability under saturated conditions. However, the geotechnical behaviour of CWG could be sensitive to its particle size and possibly deteriorate when its particle size becomes coarser, suggesting the need to determine the critical particle size of CWG beyond which its geotechnical performance may start to drop. Therefore, building on the findings of this paper and for the first time, a separate study will be presented in future that will systematically investigate and compare the geotechnical performance of CWG, as a sustainable alternative to NS and MS, for use as a column backfill in granular pile construction. Importantly, the use of CWG as an alternative geomaterial will potentially support the cleaner production concept by encouraging the use of waste glass and reducing carbon emissions. For future research, this study suggests performing a detailed techno-economic and life-cycle analysis of CWG for use in geotechnical engineering applications. 
610 The authors would like to thank Peter Lovegrove (Enviro Sand, Australia) for supplying the 611 crushed waste glass used in this study. The authors are also grateful to Anthony Neary 612 (Department of Transport and Main Roads, Queensland, Australia) for his assistance with the 613 abrasion testing of the materials. Special thanks go to Mark Raven (X-ray Fluorescence 614 Laboratory at CSIRO, Australia) for his help with the mineralogical study of the test materials. 615 Gratitude also goes to Jonathan Read (School of Mechanical and Mining Engineering at The 616 University of Queensland, Australia) for his support with the microscopic imaging of the 617 materials. Lastly, special thanks go to Sebastian Quintero (Geotechnical Engineering 618 Laboratory at The University of Queensland, Australia) for his assistance with the geotechnical 619 testing of the materials.

\section{Funding}

621 This research did not receive any specific grant from funding agencies in the public, 622 commercial, or not-for-profit sectors. 


\section{References}

1. Altuhafi, C., Georgiannou, V., 2016. Effect of particle shape on the mechanical behavior of natural sands. Journal of Geotechnical and Geoenvironmental Engineering. 142 (12), 040160711-15.

2. Amiri, S., Nazir, R., Dehghanbanadaki, A., 2018. Experimental study of geotechnical characteristics of crushed glass mixed with kaolinite soil. International Journal of Geomate. 14 (45), 170-176.

3. Arulrajah, A., Ali, M., Disfani, M., Piratheepan, J., Bo, M., 2012a. Geotechnical performance of recycled glass-waste rock blends in footpath bases. Journal of Materials in Civil Engineering. 25 (5), 653-661.

4. Arulrajah, A., Disfani, M., Maghoolpilehrood, F., Horpibulsuk, S., Udonchai, A., Imteaz, M., Du, Y., 2015. Engineering and environmental properties of foamed recycled glass as a lightweight engineering material. Journal of Cleaner Production. 94, 369-375.

5. Arulrajah, A., Piratheepan, J., Disfani, M., Bo, M., 2012b. Geotechnical and geoenvironmental properties of recycled construction and demolition materials in pavement subbase applications. Journal of Materials in Civil Engineering. 25 (8), 1077 1088.

6. Bareither, C., Edil, T., Benson, C., Mickelson, D., 2008. Geological and physical factors affecting the friction angle of compacted sands. Journal of Geotechnical and Geoenvironmental Engineering. 134 (10), 1476-1489.

7. Behrens, S., Grier, D., 2001. The charge of glass and silica surfaces. The Journal of Chemical Physics. 115 (14), 6716-6721.

8. Bogas, J., de Brito, J., Figueiredo, J., 2015. Mechanical characterization of concrete produced with recycled lightweight expanded clay aggregate concrete. Journal of Cleaner Production. 89, 187-195.

9. Bowman, E., Soga, K., Drummond, W., 2001. Particle shape characterisation using Fourier descriptor analysis. Geotechnique, 51 (6), 545-554.

10. Bravo, M., De Brito, J., Pontes, J., Evangelista, L., 2015. Mechanical performance of concrete made with aggregates from construction and demolition waste recycling plants. Journal of Cleaner Production. 99, 59-74.

11. Carter, R., Yan, Y., 2005. Measurement of particle shape using digital imaging techniques. Journal of Physics: Conference Series. 15, 177-182.

12. Cement Concrete and Aggregates Australia. (2011). Performance Benchmarking of Australian Business Regulation: Planning, Zoning and Development Assessments Retrieved from https://www.pc.gov.au/inquiries/completed/regulation-benchmarkingplanning/submissions/sub054.pdf (accessed 18 Aug 2020)

13. Chan, Y., 2003. Biostatistics 101: Data Presentation. Singapore medical journal. 44 (6), 280-285.

14. Chen, B., Zhu, H., Li, B., Sham, M., Li, Z., 2020. Study on the fire resistance performance of cementitious composites containing recycled glass cullets (RGCs). Construction and Building Materials. 242, 1179921-9.

15. Chetia, M., Baruah, M., Sridharan, A., 2017. Effect of quarry dust on compaction characteristics of clay. Contemporary Issues in Geoenvironmental Engineering. 78100.

16. Cho, G., Dodds, J., Santamarina, J., 2006. Particle shape effects on packing density, stiffness, and strength: natural and crushed sands. Journal of Geotechnical and Geoenvironmental Engineering. 132 (5), 591-602. 
17. Clean Washington Center. 1998. A tool kit for the use of post-consumer glass as a construction aggregate. Report\#: GL-97-5. Seattle, WA, USA.

18. Criss, R., Winston, W., 2008. Do Nash values have value? Discussion and alternate proposals. Hydrological Processes. 22 (14), 2723-2725.

19. Das, B., 2009. Principles of Geotechnical Engineering. Seventh edition, Cengage Learning.

20. Dai, B., Yang, J., Zhou, C., 2016. Observed effects of interparticle friction and particle size on shear behavior of granular materials. International Journal of Geomechanics. 16 (1), 040150111-11.

21. Department of Agriculture, Water and the Environment. 2013. National Waste Report. Retrieved from: https://www.environment.gov.au/protection/waste-resource-recovery/national-wastereports/national-waste-report-2013/infrastructure (accessed 15 Aug 2020)

22. Dhir, R., de Brito, J., Ghataora, G., Lye, C., 2018. Sustainable Construction Materials: Glass Cullet. Woodhead Publishing.

23. Dhir, R., de Brito, J., Silva, R., Lye, C., 2019. Sustainable Construction Materials: Recycled Aggregates. Woodhead Publishing.

24. Disfani, M., Arulrajah, A., Ali, M., Bo, M., 2011a. Fine recycled glass: a sustainable alternative to natural aggregates. International Journal of Geotechnical Engineering. 5 (3), 255-266.

25. Disfani, M., Arulrajah, A., Bo, M., Hankour, R., 2011b. Recycled crushed glass in road work applications. Waste Management. 31 (11), 2341-2351.

26. Durowaye, S., Sekunowo, O., Lawal, A., Ojo, O., 2017. Development and characterisation of iron millscale particle reinforced ceramic matrix composite. Journal of Taibah University for Science. 11 (4), 634-644.

27. Dyer, P., Klinsky, L., Silva, S., Lima, M., 2020. Mechanical and structural assessment of hot mix bituminous mixtures containing waste foundry sand. International Journal of Pavement Engineering, 1-12. DOI: https://doi.org/10.1080/10298436.2020.1724290

28. Emery, J. 1974. Use of Mining and Metallurgical Wastes in Construction. Transportation Research Board.

29. Eurostat .2020. Packaging waste statistics. Retrieved from: https://ec.europa.eu/eurostat/statisticsexplained/index.php/Packaging_waste_statistics\#Waste_generation_by_packaging_m aterial

30. Frosch, R., Gallopoulos, N., 1989. Strategies for manufacturing. Scientific American. 261 (3), 144-153.

31. Ganti, A., 2019. Central Limit Theorem (CLT). Retrieved from: https://www.investopedia.com/terms/c/central limit theorem.asp

32. Hazen, A., 1892. Some physical properties of sands and gravels, with special reference to their use in filtration. 24th Annual Rep., Publ. Doc. no. 34, 539-556, Massachusetts State Board of Health, Boston, USA.

33. Hawkins, A., 1993. The Shape of Powder-Particle Outlines. Wiley, New York.

34. Hebhoub, H., Aoun, H., Belachia, M., Houari, H., Ghorbel E., 2011. Use of waste marble aggregates in concrete. Construction and Building Materials 25 (3), 1167-1171.

35. Holmstrom, O., Swan, C., 1999. Geotechnical properties of innovative, synthetic lightweight aggregates. 1999 International Ash Utilization Symposium. Center for Applied Energy Research, University of Kentucky, Paper\# 49.

36. Holubec, I., D'appolonia, E., 1973. Effect of particle shape on the engineering properties of granular soils. Evaluation of relative density and its role in geotechnical 
projects involving cohesionless soils, ASTM STP 523, American Society for Testing and Materials. 304-318.

37. Islam, M., Siddika, A., Hossain, M., Rahman, A., Asad, M., 2019. Effect of particle size on the shear strength behavior of sands. Australian Geomechanics. 46 (3), 75-86.

38. Jonah, F., Adjei-Boateng, D., Agbo, N., Mensah, E., Edziyie, R., 2015. Assessment of sand and stone mining along the coastline of Cape Coast, Ghana. Annals of GIS. 21 (3), 223-231.

39. Kaza, S., Yao, L., Bhada-Tata, P., Woerden, F., 2018. What a Waste 2.0: A Global Snapshot of Solid Waste Management to 2050. Urban Development. Washington, DC: World Bank.

40. Koehnken, L., Rintoul, M., Goichot, M., Tickner, D., Loftus, A., Acreman, M., 2020. Impacts of riverine sand mining on freshwater ecosystems: A review of the scientific evidence and guidance for future research. River Research and Applications. 36 (3), 362-370.

41. Hossain, Z., Indraratna, B., Darve, F., Thakur, P., 2007. DEM analysis of angular ballast breakage under cyclic loading. Geomechanics and Geoengineering: An International Journal. 2 (3), 175-181.

42. Jani, Y., Hogland, W., 2014. Waste glass in the production of cement and concrete-A review. Journal of Environmental Chemical Engineering. 2 (3), 1767-1775.

43. Kazmi, D., Williams, D., Serati, M., 2019a. Comparison of Basic Geotechnical Parameters of Crushed Waste Glass with Natural and Manufactured Sands. $53^{\text {rd }}$ US Rock Mechanics/Geomechanics Symposium. New York, USA. ARMA-2019-0312.

44. Kazmi, D., Williams, D., Serati, M., 2019b. Waste Glass in Civil Engineering Applications - A Review. International Journal of Applied Ceramic Technology. 17 (2), 529-554. DOI: https://doi.org/10.1111/ijac.13434

45. Kelly, T., 1998. Crushed Cement Concrete Substitution for Construction Aggregates A Materials Flow Analysis. US Department of the Interior, US Geological Circular.

46. Koehnken, L., Rintoul,M., 2018. Impacts of Sand mining on ecosystem structure, process and biodiversity in rivers. WWF.

47. Kumar, P., Radhakrishna., 2016. Characteristics of SCC with Fly Ash and Manufactured Sand. Materials Science and Engineering. 149 (1), 1-9.

48. Lackenby, J., 2006. Triaxial behaviour of ballast and the role of confining pressure under cyclic loading. $\mathrm{PhD}$ Thesis, University of Wollongong. https://ro.uow.edu.au/theses/516/

49. Lee,J., Smith, M., Smith, L., 2007. A new approach to the three-dimensional quantification of angularity using image analysis of the size and form of coarse aggregates. Engineering Geology. 91 (2-4), 254-264.

50. Lees, G., 1964. A new method for determining the angularity of particles. Sedimentology. 3 (1), 2-21.

51. Mahmoud, E., 2005. Development of experimental methods for the evaluation of aggregate resistance to polishing, abrasion, and breakage. PhD Thesis, Texas A\&M University. https://oaktrust.library.tamu.edu/handle/1969.1/4959

52. Marangoni, M., Secco, M., Parisatto, M., Artioli, G., Bernardo, E., Colombo, P., Altlasi, H., Binmajed, M., Binhussain., 2014. Cellular glass-ceramics from a self foaming mixture of glass and basalt scoria. Journal of Non-Crystalline Solids. 403, 38-46.

53. McKelvey, D., Sivakumar, V., Bell, A., McLaverty, G., 2002. Shear strength of recycled construction materials intended for use in vibro ground improvement. Proceedings of the Institution of Civil Engineers-Ground Improvement. 6 (2), 59-68. 
54. McCuen, R., Knight, Z., \& Cutter, A., 2006. Evaluation of the Nash-Sutcliffe efficiency index. Journal of hydrologic engineering. 11 (6), 597-602.

55. Mishra, P., Suman, S., Das, S., 2017. Experimental investigation and prediction models for thermal conductivity of biomodified buffer materials for hazardous waste disposal. Journal of Hazardous, Toxic, and Radioactive Waste. 21 (2), 04016011-13.

56. Mishra, P., Bore, T., Jiang, Y., Scheuermann, A., Li, L., 2018. Dielectric spectroscopy measurements on kaolin suspensions for sediment concentration monitoring. Measurement. 121, 160-169.

57. Murray, A., Skene, K., Haynes, K., 2017. The circular economy: An Interdisciplinary Exploration of the Concept and Application in a Global Context. Journal of business ethics. 140 (3), 369-380.

58. Muszynski, M., Vitton, S., 2012. Particle shape Estimates of Uniform Sands: Visual and Automated Methods Comparison. Journal of Materials in Civil Engineering. 24 (2), 194-206.

59. Nash, J., Sutcliffe, J., 1970. River flow forecasting through conceptual models part I-A discussion of principles. Journal of Hydrology. 10 (3), 282-290.

60. Nichols, G., 2009. Sedimentology and stratigraphy. John Wiley \& Sons.

61. Park, S., Lee, B., 2004. Studies on expansion properties in mortar containing waste glass and fibers. Cement and concrete research. 34 (7), 1145-1152.

62. Patel, \& Vashi. 2015. Characterization and treatment of textile wastewater. Elsevier.

63. Peduzzi, P., 2014. Sand, rarer than one thinks. Environmental Development. 11, 208218.

64. Peng, C., Scorpio, D., Kibert, C., 1997. Strategies for successful construction and demolition waste recycling operations. Construction Management \& Economics, 15 (1), 49-58.

65. Pickin, J., Randell, P., Trinh, J., Grant, B., 2018. National Waste Report 2018. Retrieved from: https://www.environment.gov.au/system/files/resources/7381c1de-31d0-429b-912c91a6dbc83af7/files/national-waste-report-2018.pdf

66. Qing-bing, L., XIANG, W., Lehane, B., 2011. Experimental study of effect of particle shapes on shear strength of sand and tip resistance of driven piles. Chinese Journal of Rock Mechanics and Engineering. 30 (2), 400-410.

67. Rashad, A., 2014. Recycled waste glass as fine aggregate replacement in cementitious materials based on Portland cement. Construction and Building Materials. 72, 340-357.

68. Russell, R., Taylor, R., 1937. Roundness and shape of Mississippi River sands. The Journal of Geology. 45 (3), 225-267.

69. Scott, B., Safiuddin, M., 2015. Abrasion resistance of concrete-design, construction and case study. Concrete Research Letters. 6 (3), 136-148.

70. Salamatpoor, S., Salamatpoor, S., 2017. Evaluation of adding crushed glass to different combinations of cement-stabilized sand. International Journal of Geo-Engineering. 8 (1), 8 .

71. Santamarina, J., Cho, G., 2015. Soil behaviour: The role of particle shape. Advances in geotechnical engineering: The skempton conference.

72. Shinohara, K., Oida, M., Golman, B., 2000. Effect of particle shape on angle of internal friction by triaxial compression test. Powder technology. 107 (1-2), 131-136.

73. Shishkin, A., Baronins, J., Mironovs, V., Lukáč, F., Štubňa, Igor., Ozolins, J., 2020. Influence of Glass Additions on Illitic Clay Ceramics. Materials. 13 (3), 596. 
74. So, S., Lee, R., Hui, T., Shiu, Y., 2016. Study of using recycled glass cullet as an engineering fill in reclamation and earthworks in Hong Kong. Japanese Geotechnical Society Special Publication. 2 (54), 1874-1879.

75. Stahel, W., 2016. The circular economy. Nature. 531 (7595), 435-438.

76. Sukumaran, B., Ashmawy, A., 2001. Quantitative characterisation of the geometry of discret particles. Geotechnique. 51 (7), 619-627.

77. Uthus, L., Hoff, I., Horvli, I., 2019. Evaluation of grain shape characterization methods for unbound aggregates. Proceedings of the International Conferences on the Bearing Capacity of Roads, Railways, and Airfields.

78. Vallejo, L., Zhou, Y., 1995. The relationship between the fractal dimension and Krumbein's roundness number. Soils and Foundations. 35 (1), 163-167.

79. Vining, J., Linn, N., Burdge, R., 1992. Why recycle? A comparison of recycling motivations in four communities. Environmental management. 16 (6), 785-797.

80. WACA. 2018. What can be done about West Africa's Disappearing Sand? World Bank Group. Retrieved from:

http://documents1.worldbank.org/curated/en/501101527764779933/pdf/KS-Whatcan-be-done-about-West-Africas-disappearing-sand.pdf

81. Wadell, H., 1932. Volume, shape, and roundness of rock particles. The Journal of Geology, 40 (5), 443-451.

82. Wartman, J., Grubb, D., Nasim, A., 2004. Select engineering characteristics of crushed glass. Journal of Materials in Civil Engineering. 16 (6), 526-539.

83. Wettimuny, R., Penumadu, D., 2004. Application of Fourier analysis to digital imaging for particle shape analysis. Journal of Computing in Civil Engineering. 18 (1), 2-9.

84. Woodford, C., 2019. Recycling. Retrieved from https://www.explainthatstuff.com/recycling.html

85. Wu, Y., Parker, F., Kandhal, P., 1998. Aggregate toughness/abrasion resistance and durability/soundness tests related to asphalt concrete performance in pavements. Transportation Research Record. 1638 (1), 85-93.

86. Xu, Y., Wu, S., Williams, D., Serati, M., 2018a. Determination of peak and ultimate shear strength parameters of compacted clay. Engineering Geology. 243, 160-167.

87. Xu, Y., Methiwala, J., Williams, D., Serati, M., 2018b. Strength and consolidation characteristics of clay with geotextile-encased sand column. Proceedings of the Institution of Civil Engineers-Ground Improvement. 171 (3), 125-134.

88. Xu, Y., Williams, D., Serati, M., Vangsness, T., 2018. Effects of scalping on direct shear strength of crusher run and crusher run/geogrid interface. Journal of Materials in Civil Engineering. 30 (9), 0401820611-12.

89. Zhao, S., Zhou, X., Liu, W., 2015. Discrete element simulations of direct shear tests with particle angularity effect. Granular Matter. 17 (6), 793-806.

90. Zheng, J., Hryciw, R., 2016. Roundness and sphericity of soil particles in assemblies by computational geometry. Journal of Computing in Civil Engineering. 30 (6), 04016021-13.

91. Zukri, A., Nazir, R., 2018. Sustainable materials used as stone column filler: A short review. Materials Science and Engineering. 342 (1), 012001. 
896

897

898

899

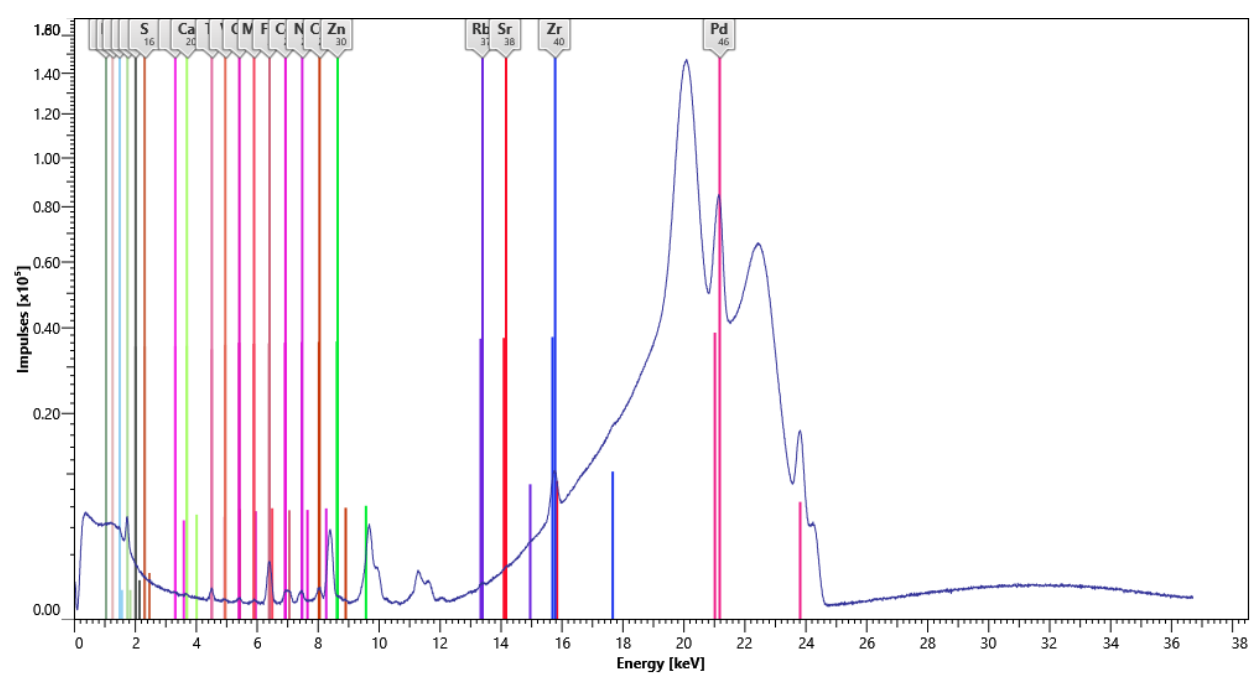

(a)

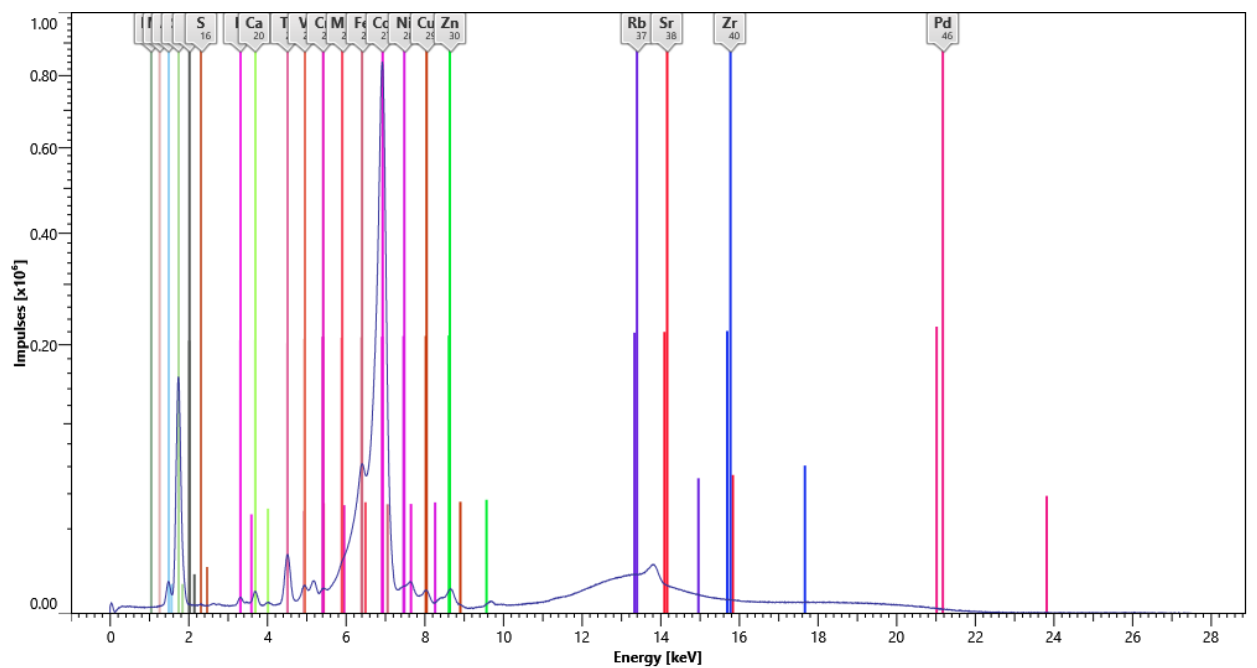

(b)

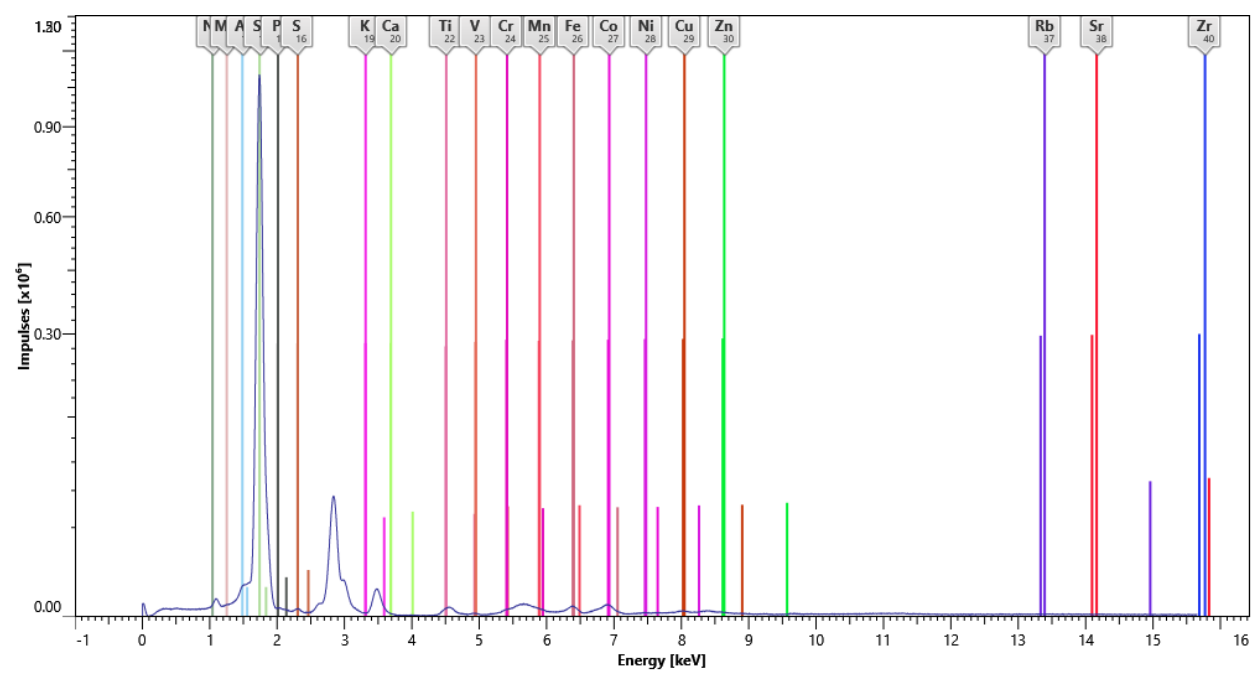

(c)

Fig. A.1 XRF spectra of NS 


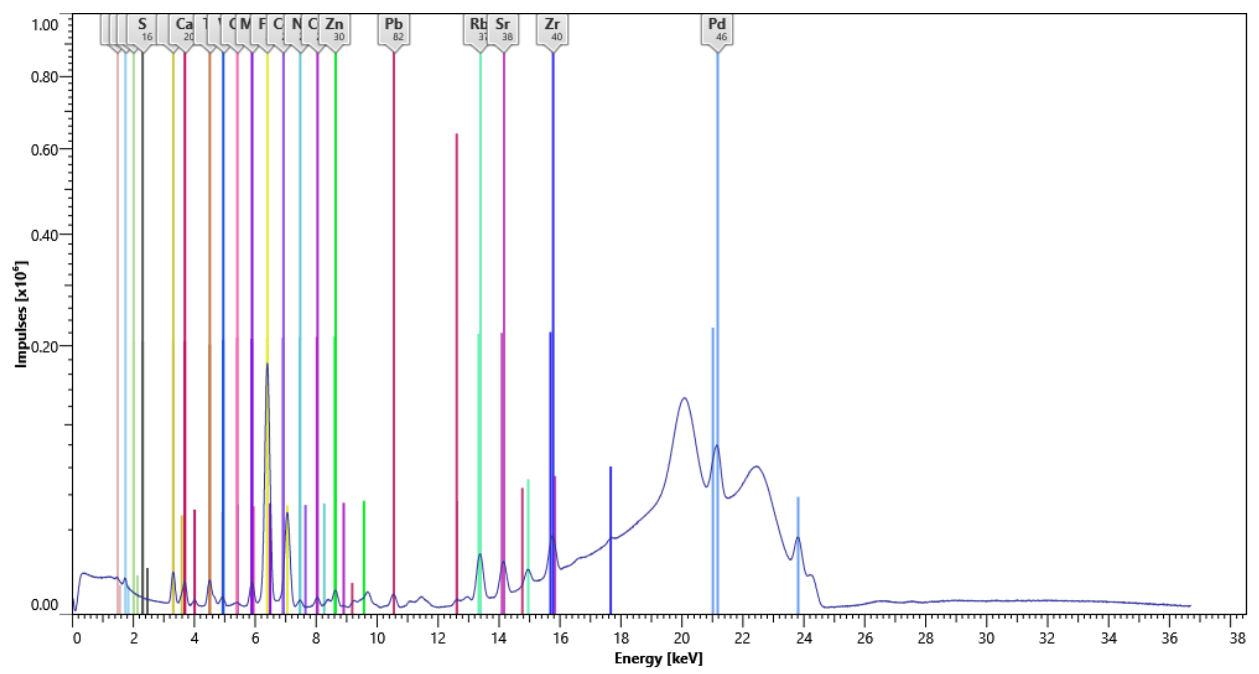

903

904

905

906

(a)

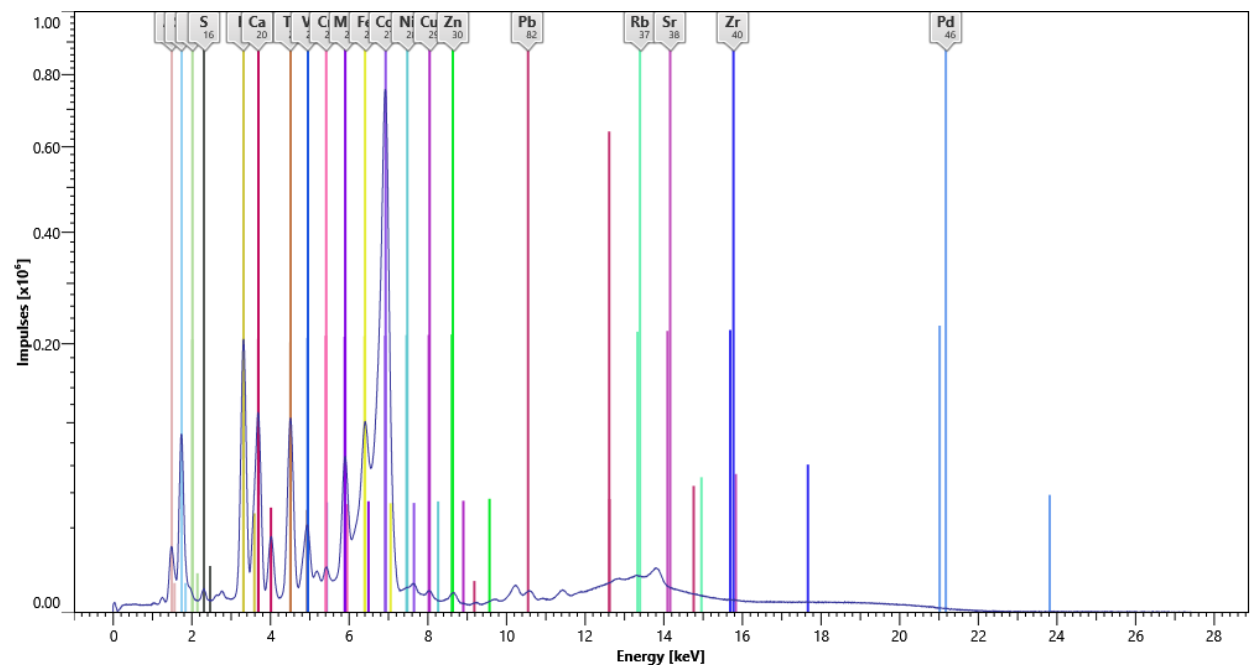

(b)

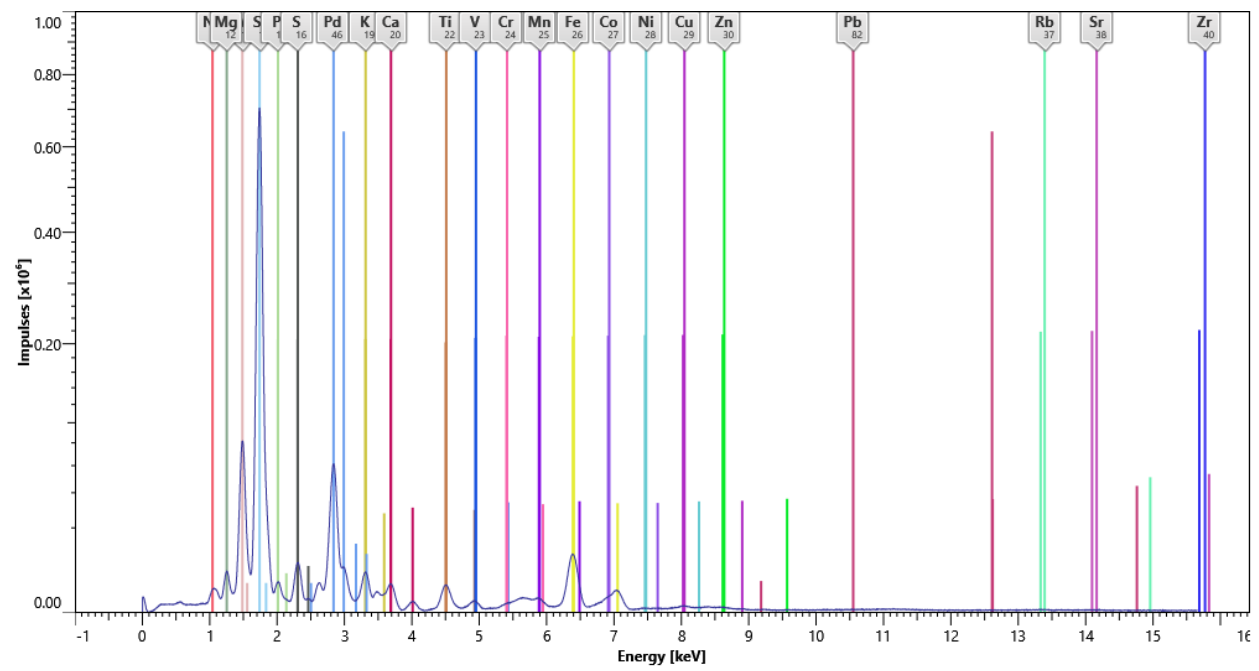

(c)

Fig. A.2 XRF spectra of MS 


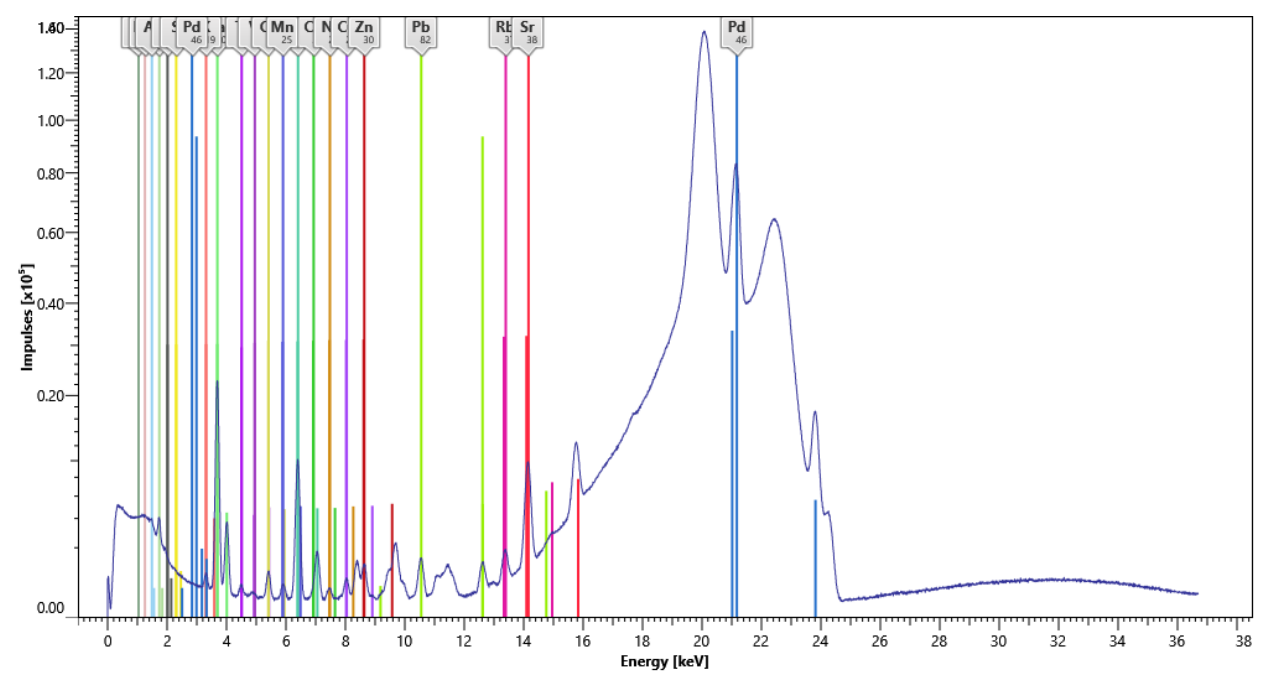

(a)

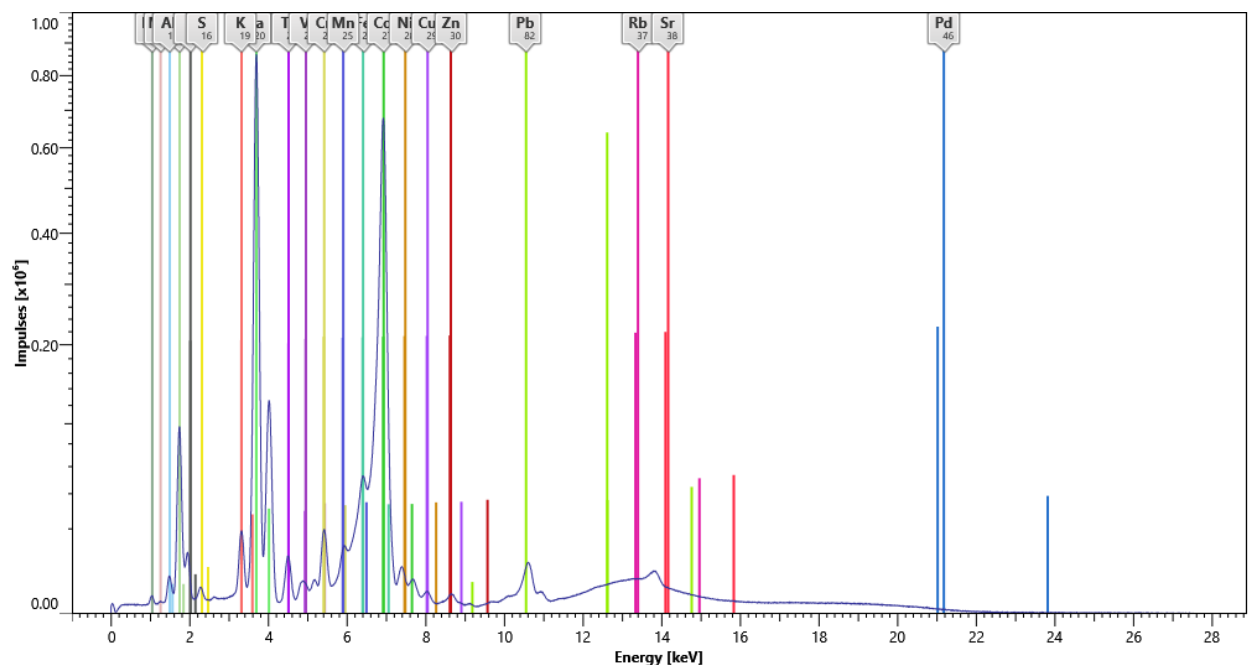

(b)

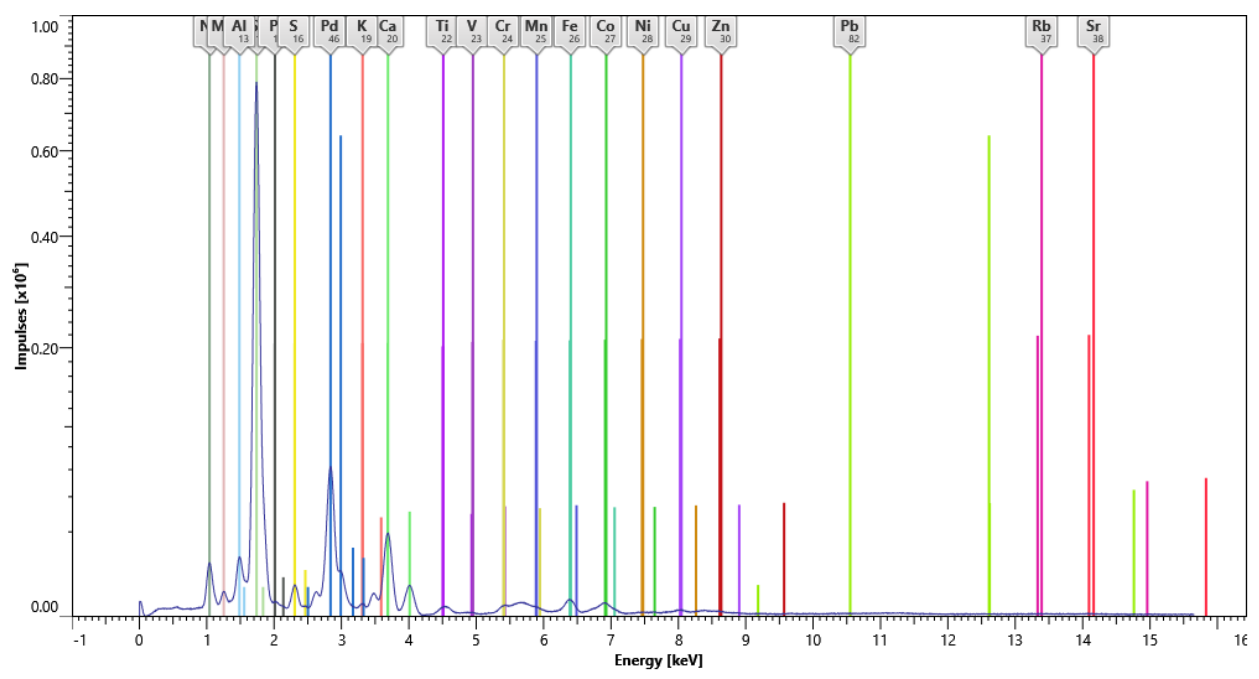

(c)

Fig. A.3 XRF spectra of CWG 